\title{
RNAi AND mIRNA PATHWAYS IN ARTHROPODS
}

Keywords: dsRNA, PKR, Dicer, R2D2, LOQS, AGO1, AGO2

\author{
PETR SVOBODA \\ Institute of Molecular Genetics, Academy of Sciences of the Czech Republic, \\ Videnska 1083, 14220 Prague 4, Czech Republic \\ Correspondence to: Petr Svoboda, Institute of Molecular Genetics ASCR, \\ Videnska 1083, 14220 Prague 4, Czech Republic, tel. \# +420 241063147, \\ e-mail: svobodap@img.cas.cz.
}

\begin{abstract}
RNA silencing denotes sequence-specific repression mediated by small RNAs. In vertebrates, there are two closely related pathways, which share several protein factors: RNA interference (RNAi) and microRNA (miRNA) pathway. The miRNA pathway regulates endogenous protein-coding gene expression and has been implicated in many biological processes. RNAi generally serves as a form of innate immunity targeting viruses and mobile elements. While Arthropoda are an extremely large and diverse phylum, research on microRNA (miRNA) and RNA interference (RNAi) pathway in this phylum primarily used the Drosophila melanogaster model system and related species. Notably, both pathways are genetically separated; they utilize dedicated Dicer proteins to produce miRNAs and small interfering RNAs (siRNAs), which are sorted onto different Argonaute effector proteins. This review focuses on the miRNA pathway and pathways initiated by long dsRNA in arthropods. The first part introduces the key molecular players of RNA silencing. The second discussed biological roles of miRNA and dsRNA-induced pathways in Arthropods.
\end{abstract}

\section{Introduction}

Arthropoda are an extremely large and diverse group of animals. In fact, they are the largest animal group on Earth with a million of named species ( $~ 80 \%$ of described animal species!) and estimated tens of millions of species (Margulis and Schwartz, 1998). Arthropoda are typically classified into five subphyla (Fig. 1). (Regier et al., 2010). Trilobita are a famous extinct group of marine animals that declined in the Late Devonian extinction and completely disappeared in the Permian-Triassic extinction. Chelicerata include living fossil horseshoe crabs, spiders, mites, ticks, scorpions and related organisms. Their characteristic features are chelicerae appendages, which appear in scorpions and horseshoe crabs as claws while spiders use them to inject venom. Myriapoda have repetitive body segments carrying one or two pairs of legs and include centipedes, millipedes, and their relatives. Crustacea 


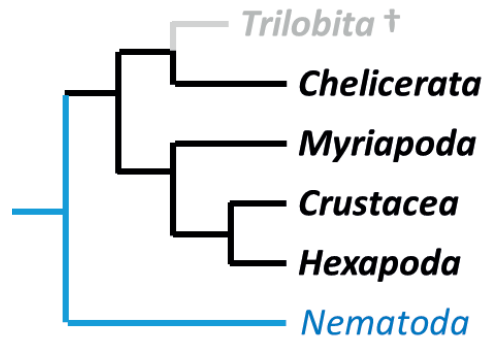

Figure 1 Simplified division of Arthropoda used in the text

The scheme reflects the Mandibulata model of arthropod phylogenetics described in (Regier et al., 2010)

are with, some exceptions (e.g. armadillo bug an relatives known as woodlice), aquatic and have differentiated segmented body and biramous appendages. They include shrimp, crayfish, lobsters, crabs, barnacles, prawns and others. Hexapoda comprise insects and insect-like animals with six thoracic legs.

The key model organism for arthropods is Drosophila, which has been a workhorse of biology for over hundred years. miRNA, RNAi and other dsRNA pathways in Drosophila are well understood and will serve as benchmarks for the entire phylum. Drosophila evolved an extensive genetic separation of miRNA and RNAi pathways where each pathway has a dedicated Dicer, dsRBP, and Argonaute protein. Given the complexity of the phylum and evolutionary time, one could question how representative of arthropods is the Drosophila model. However, analysis of Dicer and AGO indicates that Drosophila is a more-or-less acceptable model for most arthropods as the "two Dicer system" can be recognized within phylogeny of Dicer and AGOs also in Chelicerata (whose common ancestors with Drosophila branched in the most distant past), Myriapoda, and Crustacea (Palmer and Jiggins, 2015). However, it should be kept in mind that some variability could emerge during half a billion years of arthropod evolution.

Since mechanistical principles of vertebrate miRNA and RNAi pathways were introduced in the first review of this series (Svoboda, 2019) and in further detail elsewhere (Bartel, 2018), I will focus here directly on features of these pathways discovered in Arthropods. The formal structure of the report will be as in other animal taxons - upon miRNA dna RNAi molecular features of key individual components of reviewed mechanisms, I will discuss the silencing mechanisms and their biological roles. Importantly, to provide an overview of miRNA and dsRNA mechanisms in arthropods, I will focus on description of molecular mechanisms identified in Drosophila and will highlight and discuss significant deviations observed elsewhere in arthropods, especially in more studied organisms, such as mosquitos, flower beetle, silk moth, and shrimps.

\section{The Microprocessor complex}

Drosophila utilizes the same Microprocessor complex as the earlier discussed Metazoa, i.e. a complex of Drosha and DGCR8 homologs, the latter being named Pasha (partner of 
Drosha) (Denli et al., 2004; Filippov et al., 2000; Landthaler et al., 2004). The complex cleaves the pri-miRNA into pre-miRNA in the nucleus. Suppression of Pasha in Drosophila interferes with pri-miRNA processing, leading to an accumulation of pri-miRNAs and a reduction in mature miRNAs (Denli et al., 2004; Landthaler et al., 2004). Like in other animals, Pasha is essential for processing of canonical miRNAs but is dispensable for mirtrons (Flynt et al., 2010; Martin et al., 2009; Smibert et al., 2011). Drosophila Pasha is possibly phosphorylated by ERK/MAPK, as suggested by phosphorylation of human DGCR8 in insect cells; the phosphorylation appears to increase protein stability without altering miRNA processing activity (Herbert et al., 2013). miRNA biogenesis in Drosophila also involves SmD1, a component of the Drosophila small nuclear ribonucleoprotein particle (snRNP), which interacts with both the microprocessor component Pasha and pri-miRNAs, and is indispensable for optimal miRNA biogenesis (Xiong et al., 2015).

Analysis of transcriptome changes upon Drosha knock-down in S2 cells identified 137 Drosha-regulated RNAs, including 11 relatively long $(>10 \mathrm{~kb}$ ) pri-miRNAs (Kadener et al., 2009). Interestingly, $>100$ RNAs not annotated as miRNAs could be direct targets of Drosha action (Kadener et al., 2009), which is consistent with other model systems where Drosha is having roles beyond miRNA biogenesis. Drosha-regulated RNAs contain conserved hairpins similar to those recognized by the Drosha-Pasha/DGCR8 complex in pri-miRNAs, one of such hairpins is found also in Pasha suggesting a negative feedback loop regulating miRNA-biogenesis (Kadener et al., 2009). miRNA-independent roles of the Microprocessor complex components seem to be reflected in phenotypes of some of their mutants (Luhur et al., 2014).

In terms of evolutionary diversity of the Microprocessor complex in arthropods, the miRNA pathway seemed to expand in the pea aphid (insect, Hemiptera), whose genome carries four expressed copies of Pasha (Jaubert-Possamai et al., 2010). At the same time, the brown planthopper (insect, Hemiptera), the fall armyworm (insect, Lepidoptera) or the desert locust (insect, Orthoptera) all have a single Pasha (Ghosh et al., 2014; Wynant et al., 2015; Xu et al., 2013), which appears the common case among arthropods when browsing available genome databases. Analysis of Pasha in Litopenaeus vannamei (shrimp) revealed high sequence conservation and nuclear localization, suggesting a well-conserved role in miRNA biogenesis (Chen et al., 2012). Conservation of miRNA pathway in shrimps is further supported by requirement for Drosha, Dicer1 and Agol for production of viral RNAs in infected shrimps (He and Zhang, 2012; Huang et al., 2012).

\section{Dicer}

Drosophila utilizes two Dicer proteins (Fig. 2), Dicer-1 (DCR-1) and Dicer-2 (DCR-2), which are dedicated to miRNA and RNAi pathways, respectively (Lee et al., 2004). This makes Drosophila (and arthropods in general) unique among the reviewed metazoan model systems (Fig. 3), which employ a single Dicer protein producing multiple classes of small RNAs (miRNAs, endo-siRNAs, exo-siRNAs). Separation of miRNA and RNAi at Dicer level could have an advantage in terms of uncoupling antagonistic evolutionary forces acting on Dicer, i.e. (i) selective pressure on conservation of the miRNA pathway machinery 


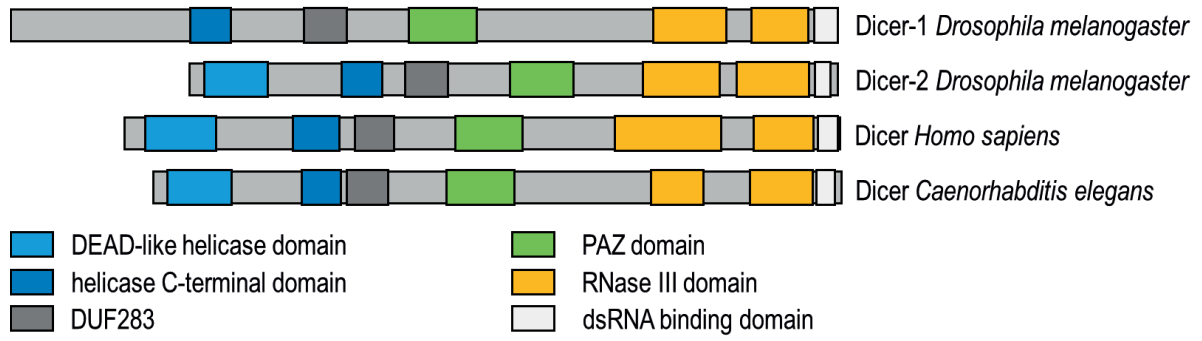

Figure 2 Comparison of $C$. elegans, human and Drosophila Dicer proteins Domain composition was adopted from (Jaskiewicz and Filipowicz, 2008).

and (ii) host-pathogen arms race where Dicer evolves to avoid viral proteins interfering with its function.

The domain organization of Drosophila Dicer proteins is generally the same as in other metazoan Dicer proteins - they are composed of domains ordered from the N- to the C-terminus as follows: N-terminal helicase domains, a domain of unknown function DUF283, PAZ domain, RNase IIIa and RNase IIIb domains, and the C-terminal dsRBD (Fig. 2). As for other metazoan Dicers, Drosophila Dicer proteins have not been crystallized yet but their structure can be inferred from biochemical studies of recombinant Dicer and individual domains (Tsutsumi et al., 2011; Ye et al., 2007), the crystal structure of Giardia intestinalis Dicer (MacRae et al., 2007; MacRae et al., 2006), domain modelling or cryo-EM studies (Lau et al., 2012).

\section{Dicer-1}

Dicer-1 was originally identified as one of two homologs in Drosophila, which was able to produce siRNAs in vitro and participated in RNAi (Bernstein et al., 2001). Subsequent analysis of Dicer mutants showed that mutation in dicer-1 blocked processing of miRNA precursors while dicer-2 mutants were defective for processing siRNA precursors (Lee et al., 2004). However, consistent with the initial study, Dicer-1 was also implicated in RNAi (Lee et al., 2004). Biochemical analysis of Dicer-1 showed that its functional core consists of a DUF283 domain, a PAZ domain, and two RIII domains (Ye et al., 2007). With respect to the size of cleavage products, Dicer-1 apparently does not differ from other metazoan Dicers, as the typical product size is $22 \mathrm{nt}$ long (Fig. 4). DCR-1 also functions in biogenesis of mirtron class of miRNAs (Okamura et al., 2007).

Dicer-1 differs from Dicer-2 in substrate specificities and ATP requirements (Jiang et al., 2005). Like human Dicer, Dicer-1 generates small RNAs in an ATP-independent manner (Jiang et al., 2005), whereas Dicer-2 or Dicer-2/R2D2 required ATP hydrolysis for efficient siRNA production (Liu et al., 2003). Dicer-1 shows a preference for pre-miRNAs (Jiang et al., 2005; Tsutsumi et al., 2011). It recognizes the single-stranded terminal loop structure of pre-miRNAs through its N-terminal helicase domain, checks the loop size and measures the distance between the $3^{\prime}$ overhang and the terminal loop - this allows Dicer-1 to inspect the authenticity of pre-miRNA structures (Tsutsumi et al., 2011). 
In terms of evolutionary diversity of Dicer-1 in arthropods, as mentioned above, the miRNA pathway seemed to expand in pea aphid (insect, Hemiptera) which utilizes two active copies of Dicer 1 (Jaubert-Possamai et al., 2010; Ortiz-Rivas et al., 2012). However, this duplication is a relatively recent event while single Dicer-1 was also identified elsewhere among arthropods (Jaubert-Possamai et al., 2010; Ortiz-Rivas et al., 2012), including shrimp (Su et al., 2008), mosquito (Bernhardt et al., 2012), cockroach (Gomez-Orte and Belles, 2009) or locust (Wynant et al., 2015) species.

\section{Dicer-2}

Dicer-2 in Drosophila is mainly producing siRNAs from long dsRNA and functions in RNAi and antiviral defense (Galiana-Arnoux et al., 2006; Kim et al., 2006). Dicer-2 has actually a dual role in antiviral defense - apart from RNAi, it has an RNAi-independent role in promoting Toll signalling (Wang et al., 2015b), but biological aspects of Dicer-2 role will be covered later in the text.

Unlike mammalian Dicer or Dicer-1 paralog, Dicer-2 requires ATP for processive cleavage of dsRNA (Liu et al., 2003; Nykanen et al., 2001; Provost et al., 2002; Welker et al., 2011; Zhang et al., 2002). Remarkably, analysis of shapes of a mammalian Dicer and Dicer-2 by cryo-EM yielded an L-shaped reconstruction with dimensions strikingly similar to those of the human enzyme (Lau et al., 2012). Therefore, despite striking functional differences in ATP requirement and substrate preference, the overall three-dimensional architecture of Dicer is well conserved (Lau et al., 2012).

Dicer-2 contains an N-terminal helicase motif and hydrolyzes ATP; ATP hydrolysis is required for Dicer-2 to process long dsRNA, but not pre-miRNA (Cenik et al., 2011). Dicer-2 works as a dsRNA-stimulated ATPase that hydrolyzes ATP to ADP; and it was suggested that Dicer-2 helicase domain uses ATP to generate many siRNAs from a single molecule of dsRNA before dissociating from its substrate. (Cenik et al., 2011).

The helicase domain of Dicer-2 also governs substrate recognition and cleavage efficiency through discriminating among dsRNA ends. First, it was shown that the helicase domain is essential for cleaving dsRNA with blunt or 5'-overhanging termini, but not those with 3' overhangs, as in pre-miRNAs (Welker et al., 2011). Subsequently, it was found that the discrimination of termini takes place during initial binding (Sinha et al., 2015). In the absence of ATP, Dicer-2 binds 3' overhanging (pre-miRNA-like), but not blunt termini. in the presence of ATP, Dicer-2 binds both types of termini, with highest-affinity binding observed with blunt dsRNA (Sinha et al., 2015).

An important factor in substrate discrimination and processing is inorganic phosphate, which inhibits Dicer-2 cleavage of pre-miRNAs, but not long dsRNAs (Cenik et al., 2011). It was proposed that the inorganic phosphate occupies a PAZ domain 5' phosphate binding pocket required to bind the 5 ' terminal phosphate of short substrates, blocking their use and restricting pre-miRNA processing in flies to Dicer-1 (Fukunaga et al., 2014). Binding of long dsRNA is not inhibited when the inorganic phosphate occupies the PAZ domain binding pocket because it also involves the helicase domain and/or the central dsRNA-binding domain, which might be combined with displacement of the inorganic phosphate from its binding pocket (Fukunaga et al., 2014) 


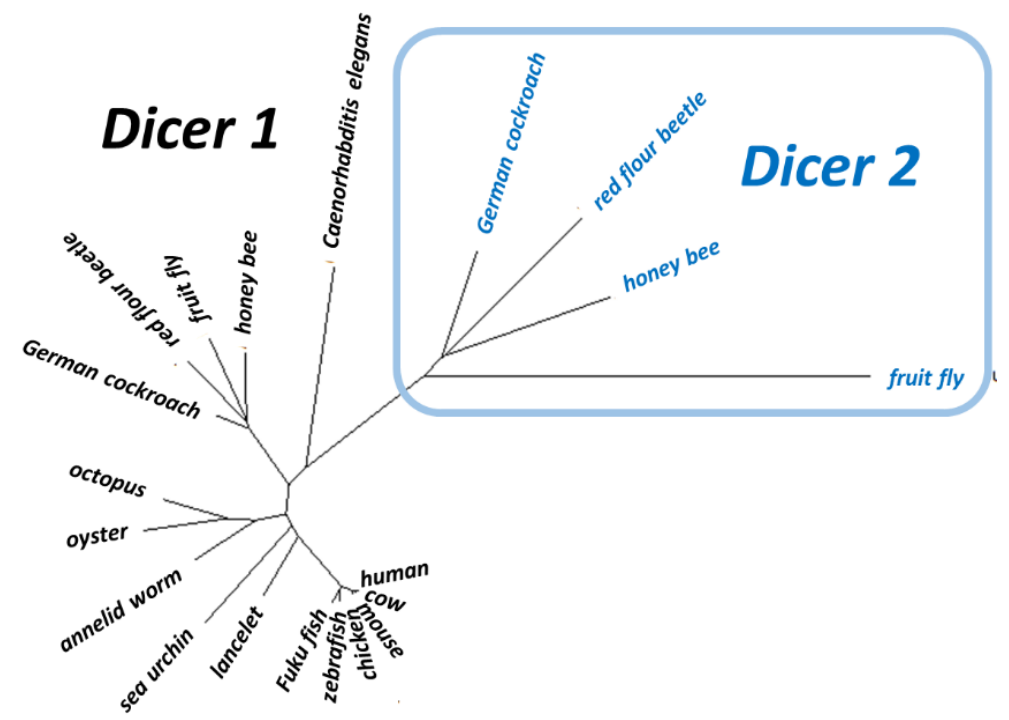

Figure 3 Metazoan Dicer phylogeny

The unrooted tree shows phylogenetic relationships of Dicer proteins in Metazoa. The blue frame depicts Dicer2 homologs in arthropods. As the length of each branch indicates evolutionary distance (or sequence divergence), it is apparent that arthropod's Dicer 2 proteins acting in RNAi are evolving at much faster pace than Dicer 1 protein, which function in the miRNA pathway. This is consistent with the above-mentioned notion of antagonistic evolutionary forces acting on Dicer where the miRNA pathway functionality is being conserved while the RNAi functionality is evolving during the host-pathogen arms race where Dicer evolves to avoid viral proteins interfering with its function.

In terms of evolutionary diversity of Dicer-2 in arthropods, most species seem to use only one Dicer-2 but some underwent duplication, such as Daphnia (Crustacea, two Dicer-2 paralogs) or Metaseiulus (Chelicerata, five Dicer-5 paralogs) (Palmer and Jiggins, 2015). Among the experimentally approached species, one Dicer-2 was reported in experimental results from silk moth (Kolliopoulou and Swevers, 2013), mosquito (Leger et al., 2013), cockroach (Lozano et al., 2012), Hessian fly (Kolliopoulou and Swevers, 2013), planthopper (Zhang et al., 2013), emerald ash borer (Zhao et al., 2015), mite (Hoy et al., 2016), bumble bee (Niu et al., 2016), or shrimp (Niu et al., 2016).

\section{dsRBPs in arthropods - R2D2 and LOQS homologs}

Drosophila also utilizes Dicer partner dsRBPs with tandemly arranged dsRBDs - Loquacious (LOQS) and R2D2. The first Dicer partner dsRBP in Drosophila is Loquacious, which was found to associate with Dicer-1, suggesting that the miRNA pathway in Drosophila employs a distinct dsRBP in substrate routing (Forstemann et al., 2005; Saito et al., 2005). However, it was also found that Dicer-2-generated siRNAs in the endogenous RNAi pathway depend preferentially on Loquacious and not on R2D2, the canonical Dicer-2 partner 
(Czech et al., 2008). it turned out that Loquacious gene actually produces three protein isoforms, which associate with Dicer-1 and miRNA pathway (LOQS-PA and LOQS-PB isoform) and Dicer-2 and RNAi (LOQS-PD isoform) (Fukunaga et al., 2012; Hartig et al., 2009; Miyoshi et al., 2010a; Zhou et al., 2009).

LOQS-PB uses the second dsRNA-binding domain to bind pre-miRNA and the third dsRNA-binding domain to interact with Dcr-1. Both domains of LOQS-PB are required for efficient miRNA production by enhancing the affinity of Dcr-1 for pre-miRNA (Ye et al., 2007).

LOQS-PD and R2D2 function sequentially and non-redundantly in the endogenous RNAi pathway. LOQS-PD stimulates DCR-2-mediated processing of dsRNA whereas R2D2 acts downstream during RISC loading (Hartig and Forstemann, 2011; Marques et al., 2010; Miyoshi et al., 2010a). Taken together, LOQS and R2D2 contribute to the profound mechanistic separation of miRNA and RNAi pathways, which evolved in Drosophila (and presumably in arthropods in general).

R2D2 associates with Dicer-2 and acts in RNAi; it was co-purified with Dicer-2 during purifying siRNA-generating activity from Drosophila S2 cell lysates (Liu et al., 2003). Although R2D2 bears 33\% similarity to RDE-4 (see the section Nematoda) its role is different. R2D2 does not influence DCR-2 enzymatic activity (Liu et al., 2003) but restricts Dicer-2 function to processing of long dsRNAs (Cenik et al., 2011; Fukunaga et al., 2014). It also facilitates passing the cleavage product to $\mathrm{AGO} 2$ excluding miRNA-like duplexes with imperfect base pairing (Tomari et al., 2004a). R2D2 has two roles - it is sensing siRNA thermodynamic asymmetry for strand selection and it is a licensing factor for entry of authentic siRNAs into the RNAi pathway (Nishida et al., 2013; Tomari et al., 2004b).

Unlike the Microprocessor complex, Dicer or Argonautes, dsRBPs seem undergo various functional adaptations between different taxons (compare, for example TARBP2, RDE-4, R2D2 or LOQS). This possibly also happens among arthropods. An example is the lack of the RNAi-associated LOQS-PD isoform outside Drosophila (Haac et al., 2015). Analysis of dsRBPs in the mosquito Aedes aegypti revealed absence of LOQS-PD isoform, conserved roles of R2D2 and LOQS-PB, and LOQS-PA role in biogenesis of both, miRNAs and endo-siRNAs (Haac et al., 2015).

\section{Argonaute proteins}

AGO proteins of arthropods are conserved, i.e. their domain composition is the same as that of mammalian proteins, which was discussed in detail (Peters and Meister, 2007). Arthropods have varying number of Argonaute proteins of the AGO and PIWI clade but it seems that their archetypal state is two AGO proteins, each being associated with one Dicer and one type of small RNA (Palmer and Jiggins, 2015).

\section{AGO1 and its loading with miRNAs}

AGO1 RISC loading is similar to that of human RISC assembly described earlier (Yoda et al., 2010). Dicer-1/LOQS-PB heterodimer functions in assembling AGO1 RISC, which 
is preferentially loaded with miRNA/miRNA* duplexes while siRNAs are being excluded from the assembly (Tomari et al., 2007).

AGO1 requires ATP for miRISC loading, presumably to trigger the dynamic conformational opening of AGO proteins so that they can accept small-RNA duplexes (Kawamata et al., 2009). Unwinding of miRNA-miRNA* duplexes is a passive process that does not require ATP or slicer activity of Ago 1 (Kawamata et al., 2009).

Two distinct AGO complexes were identified (Miyoshi et al., 2009): (i) AGO1-Dicer-1 complex with pre-miRNA processing activity where the resultant mature RNA was loaded onto AGO1 within the complex - this complex corresponds to miRLC (miRISC loading complex) (ii) the AGO1-GW182 complex with excluded DCR-1, containing mature miRNA no pre-miRNA processing activity - this complex corresponds to miRISC. AGO1 loading also involves R3D1-L, a dsRBP that functions as a cofactor interacting with Dicer-1 and AGO1 (Jiang et al., 2005).

AGO1 might also have miRNA-independent role in translational repression where AGO1 is recruited to mRNA via an RNA-binding protein SMAUG and not through miRNA:mRNA interaction (Pinder and Smibert, 2013).

\section{AGO2 and its loading with siRNAs}

The model of RNAi RISC loading in Drosophila suggests that RISC assembly occurs in several steps, which involve a several complexes (Tomari and Zamore, 2005). The first complex is formed by siRNA, R2D2 and DCR-2, also known as R1 or R2/D2/DCR-2 initiator (RDI) complex (Kim et al., 2007; Pham et al., 2004), which develops into a mature form of the RISC loading complex RLC (Tomari and Zamore, 2005). The RLC determines strand selection and recruits AGO2 (and other proteins) to form pre-RISC (Kim et al., 2007), which contains duplex siRNA. Finally, the release of the passenger strand from the duplex produces holo-RISC, which can base pair with complementary mRNA substrates. The loading is assisted by Hsc70/Hsp90 chaperones (Iwasaki et al., 2015; Miyoshi et al., 2010b).

The coupling of dsRNA cleavage and RISC assembly is a matter of debate. It was suggested that, after cleavage, small-RNA duplexes need to dissociate from Dicer and then rebind to a sensor of the thermodynamic asymmetry of the duplex, because the guide strand of an siRNA will be at random orientation (Tomari et al., 2004b).

AGO2 requires ATP for RISC loading (Kawamata et al., 2009; Pham et al., 2004; Tomari et al., 2004a). ATP is presumably used to trigger the dynamic conformational opening of AGO proteins so that they can accept small-RNA duplexes (Kawamata et al., 2009).

Strand selection in fly RLC is controlled by R2D2. Analysis of the interaction of DCR2/R2D2 complex with siRNA duplexes showed that R2D2 orients the complex according to thermodynamic stabilities of siRNA strands and binds the 5' phosphate of the passenger strand at the thermodynamically more stable end (Tomari et al., 2004b). Thus, R2D2 functions as a licensing factor for routing siRNAs into the RNAi pathway. Interestingly, a thorough analysis of AGO2 complexes revealed that, unlike mature miRNAs, which are loaded on AGO1, complementary strands of mature miRNAs (miRNA*) are efficiently loaded on AGO2 in DCR2/R2D2-dependent manner (Ghildiyal et al., 2010; Okamura et al., 
2011). Thus, the role of R2D2 in sorting small RNAs is wider and extends into the miRNA pathway.

The final step in assembly of an active RISC is the release of the passenger strand from the siRNA duplex. Drosophila is Armitage helicase is a candidate for a mechanism separating the two siRNA strands while the guide remains bound to AGO2 (Tomari et al., 2004a). However, experimental data support a simple solution where passenger strand cleavage by AGO2 slicer activity liberates the single-stranded guide siRNA strand from the pre-RISC complex (Kim et al., 2007; Matranga et al., 2005; Miyoshi et al., 2005). Removal of siRNA passenger strand cleavage products is assisted by $\mathrm{C} 3 \mathrm{PO}$ endoribonuclease, which was identified as a RISC-enhancing factor that promotes RISC activation (Liu et al., 2009). The cleavage-assisted mechanism is typical for AGO2-loaded fly and human siRNAs in the RNAi pathway while passenger strand cleavage is not important for loading miRNAs (Matranga et al., 2005).

\section{Small RNA sorting and mRNA targeting by AGO1 and AGO2}

Drosophila sorts Dicer-produced small RNAs onto functionally distinct AGO proteins where AGO1 is dedicated to the miRNA pathway while AGO2 served for RNAi. Small RNA sorting is initiated by substrate recognition and continues through sorted loading onto the AGO proteins. Small-RNA duplexes are actively sorted into AGO-containing complexes according to their intrinsic structures (Forstemann et al., 2007; Tomari et al., 2007). Importantly, separation of miRNA and RNAi at the level of small RNA sorting onto AGO1 and AGO2 is not completely pre-determined by small RNA origins (Tomari et al., 2007). It was found that miRNA*s are often loaded as functional species into AGO2 (Czech et al., 2009; Ghildiyal et al., 2010; Okamura et al., 2009). Furthermore, miRNAs produced by Dicer-1 and LOQS can be loaded by Dicer-2 and R2D2 into an AGO2 RISC (Forstemann et al., 2007). Finally, siRNAs derived from long hairpin RNA genes (hpRNA) also show a hybrid biogenesis combining RNAi factors DIcer-2 and AGO2 and Loquacious isoform (Okamura et al., 2008c).

Subsequently, AGO2-RISC mediates RNAi while only AGO1 is able to repress mRNAs with central mismatches in miRNA-binding sites (Forstemann et al., 2007). At the same time, AGO1 cannot mediate RNAi, because it is an inefficient nuclease with a catalytic rate limited by the dissociation of reaction products (Forstemann et al., 2007). AGO1 and AGO2 RISCs also differ in mechanisms of translational repression - AGO1-RISC represses translation primarily by ATP-dependent deadenylation while Ago2-RISC competitively blocks the interaction of eIF4E with eIF4G and inhibits the cap function (Fukaya et al., 2014; Iwasaki et al., 2009). AGO1-mediated translational repression involves GW182 in the same manner as in mammals (GW182 is separately described further below). miRNA-mediated silencing involves recruitment of PABP, CCR4-NOT deadenylase and decapping complex to RISC (Behm-Ansmant et al., 2006; Chekulaeva et al., 2011; Eulalio et al., 2008; Fukaya and Tomari, 2011; Huntzinger et al., 2010; Huntzinger et al., 2013; Moretti et al., 2012; Rehwinkel et al., 2005). miRNA-mediated repression occurs on ribosome complexes but is independent of ribosomal scanning(Antic et al., 2015; Kuzuoglu-Ozturk et al., 2016). 


\section{Evolutionary perspective}

As mentioned above, the archetypal state arthropod state is two AGO proteins, AGO1 and AGO2. Apart from Drosophila, such a situation is found in Daphnia (Crustacea) and Metaseiulus (mite, Chelicerata) (Palmer and Jiggins, 2015). However, upon detailed inspection, one frequently finds variability in the number of AGO proteins across the phylum or even across smaller taxonomic units. The miRNA pathway seemed to expand in pea aphid (insect, Hemiptera), whose genome two expressed copies of ago1, one of which (agolb) shows signs of positive selection (Jaubert-Possamai et al., 2010). At the same time, a single AGO1 but duplications of AGO2 were found Ixodes (tick, Chelicerata, three AGO2 paralogs), Strigamia (centipede, Myriapoda, two AGO2 paralogs), Mesobuthus (scorpion, Chelicerata, six AGO2 paralogs) or Tetranychus (spider mite, Chelicerata, six AGO2 paralogs) (Palmer and Jiggins, 2015). Penaeus monodon (black tiger shrimp) has four functionally diversified AGO paralogs (Dechklar et al., 2008; Leebonoi et al., 2015; Phetrungnapha et al., 2013; Yang et al., 2014b). Analysis of Argonaute genes across 86 Dipteran species showed that variation in copy number can occur rapidly, and that there is constant flux in some RNAi mechanisms; this suggests that Argonautes undergo frequent evolutionary expansions that facilitate functional divergence (Lewis et al., 2016).

\section{Additional miRNA and RNAi factors}

There is a large number of accessory factors beyond those described above. For example, a systematic screen of $40 \%$ of the genome for genes acting in the miRNA pathway yielded 45 mutations in 24 genes and an estimate of $\sim 100$ genes are required to execute the miRNA program (Pressman et al., 2012). Here, we will describe several additional factors, which have been associated with miRNA or RNAi pathways.

Nibbler - Nibbler is a 3'-5; exoribonuclease involved in trimming 3' ends of miRNAs and piRNAs (Feltzin et al., 2015; Han et al., 2011; Liu et al., 2011; Wang et al., 2016; Yang et al., 2014a). In the miRNA pathway, Nibbler shortens distinct longer miRNAs during RISC assembly, yielding miRNA isoforms that are compatible with the preferred length of AGO1-bound small RNAs (Han et al., 2011; Liu et al., 2011). It has been estimated that about a quarter of miRNAs undergoes such a trimming (Han et al., 2011).

HEN1 - HEN1 (Pimet, Dmhen1)is an enzyme catalyzing addition of a 2'-O-methyl group at the 3' end of small RNAs (Horwich et al., 2007; Saito et al., 2007). While this modification is predominantly found on piRNAs in Drosophila, it was also found on siRNAs and miRNAs (Abe et al., 2014; Horwich et al., 2007; Yang et al., 2014a). Functionally, 2'-O-methylation of siRNAs loaded on $\mathrm{AGO} 2$ prevents tailing and trimming of siRNAs (Ameres et al., 2010). Generally HEN1 and Nibbler thus have antagonistic activities at the 3 ' end of small RNAs where Nibbler promotes small RNA trimming while Hen1 prevents it (Ameres et al., 2010; Yang et al., 2014a). 2'-O-methylation is also found on select miRNA isoforms and appeared to increase with age while its reduction was associated with neurodegeneration and shorter life span (Abe et al., 2014). 
nucleotidyltransferases - tailing of short RNAs is mediated by terminal nucleotidyltransferases, which produce 3' uridylation or adenylation. PAPD4 has been identified as a primary miRNA adenylating enzyme in Drosophila, adenylation did not appear to affect miRNA stability on a genome-wide scale (Burroughs et al., 2010). Another non-canonical adenylase is Wispy, which is responsible for adenylation of miRNAs and biologically it may facilitate clearance of maternal miRNAs in the embryo (Lee et al., 2014). Uridylation is mediated by Tailor, which is a uridylyltransferase that is required for the majority of 3' end modifications of microRNAs in Drosophila and predominantly targets mirtron hairpins (Reimao-Pinto et al., 2015; Westholm et al., 2012).

GW182 - GW182 is the key co-factor of AGO1 in miRISC. Its role has been described in detail in the mammalian section, he we will briefly note its key features with respect to arthropods. GW182 and its interaction with AGO1 were found to be required for miRNA-mediated repression in Drosophila cells (Behm-Ansmant et al., 2006; Eulalio et al., 2008; Rehwinkel et al., 2005). miRNA-mediated repression also required the decapping complex DCP1:DCP2 and CCR4-NOT deadenylase (Behm-Ansmant et al., 2006; Rehwinkel et al., 2005). Multiple domains of GW182 contribute to miRNA-mediated repression (Chekulaeva et al., 2009; Chekulaeva et al., 2011; Chekulaeva et al., 2010; Eulalio et al., 2009). Similarly to mammals, Drosophila GW182 directly interacts with PABP and CCR4-NOT (Chekulaeva et al., 2011; Fukaya and Tomari, 2011; Huntzinger et al., 2010; Huntzinger et al., 2013; Moretti et al., 2012).

Armitage - RNA helicase, which was identified as a maternal effect gene required for RNAi (Tomari et al., 2004a). Armitage is probably not required for RISC activity. Instead, it was proposed to facilitate removal of the passenger strand during RISC formation (Tomari et al., 2004a). Armitage was also implicated in piRNA biogenesis (Huang et al., 2014; Murota et al., 2014; Nagao et al., 2010; Qi et al., 2011; Saito et al., 2010).

dFMR1 - Drosophila ortholog of human fragile X mental retardation protein (FMRP) was identified as a RISC component (Caudy et al., 2002; Ishizuka et al., 2002; Pham et al., 2004). dFMR1 is associated with ribosomes through interaction with ribosomal proteins L5 and L1 and with complexes containing miRNAs (Ishizuka et al., 2002). dFMR1 is not a conserved RISC component involved in RNAi as depletion of dFMR1 reduces RNAi efficiency in Drosophila S2 cells but not in mammals (Caudy et al., 2002). dFMR has been also implicated in the piRNA pathway (Bozzetti et al., 2015; Jiang et al., 2016).

VIG - Vasa Intronic Gene (Caudy et al., 2002; Pham et al., 2004). VIG is a conserved protein, which encodes a putative RNA binding protein, whose depletion reduces RNAi efficiency (Caudy et al., 2002). Vig mutants are more susceptible to viral infections in Drosophila (Zambon et al., 2006). Whether this role of VIG is coupled with its presence in the RISC complex is not known. There is no evidence that SERBP1, the closest mammalian VIG homolog, would be associated with RISC. VIG was also implicated in heterochromatin formation (Gracheva et al., 2009).

Tudor-SN - Tudor Staphylococcal Nuclease is a protein containing five staphylococ$\mathrm{cal} /$ micrococcal nuclease domains and a Tudor domain. It is a component of the RISC in C. elegans, Drosophila and mammals (Caudy et al., 2003; Pham et al., 2004). The role of Tudor-SN in RISC RNAi remains enigmatic. TSN is not the „slicer“ (Schwarz et al., 2004) and its knock-down in silk moth cells had not effect on RNAi efficiency (Zhu et al., 
2012). In Drosophila, Tudor-SN has also been linked to piRNA pathway regulation (Ku et al., 2016).

DMP68 (RM62) - this conserved helicase was co-purified with AGO1 and dFMR1 (Ishizuka et al., 2002). This helicase seems to be required for RNAi in S2 cells where depletion of DMP68 results in inhibition of RNAi (Ishizuka et al., 2002). Whether DMP68 is needed for RISC formation or for RISC activity/stability is not known. Later publications on RM62 linked it to antiviral response (Zambon et al., 2006) and to other mechanisms than RNAi.

CRIF1 - the Drosophila homolog of the mammalian CR6-interacting factor 1 (CRIF1), was identified as a potential new regulator of the RNAi pathway during a screen for genetic mutations in Drosophila that alter the efficiency of RNAi. CRIF1 loss-of-function mutant flies are deficient in exo-RNAi, in siRNA biogenesis and in antiviral immunity. (Lim et al., 2014)

\section{RdRPs in arthropods}

One of the less understood areas of RNA silencing in arthropods is utilization of RdRPs. A phylogenetic analysis suggests that RdRPs in RNA silencing pathways have a monophyletic origin, i.e. evolved from a single ancestral RdRP (Cerutti and Casas-Mollano, 2006; Murphy et al., 2008). A simple TBLASTN search with C. elegans RRF-1 proteins sequence reveals RdRPs in species across Metazoa, including Cnidaria (hydra), Nematoda (RdRPs in C. elegans will be discussed later), Mollusca (oyster), Hemichordata (acorn worm), or Urochordata (sea squirt). At the same time, RdRPs seem to be absent in other groups including Platyhelminthes, Annelida, and vertebrates. What this implies for arthropods is that the common ancestors of protostomes and deuterostomes still had RdRPs and that RdRPs were repeatedly lost in different taxons. We performed a diagnostic TBLASTN search with C. elegans RRF-1 proteins sequence also for the major groups of arthropods and we have identified RdRP homologs in diverse representatives of the subphylum Chelicerata (spiders, horseshoe crab, ticks, mites) but none in the remaining subphyla - Myriapoda, Crustacea, and Hexapoda. This would suggest that RdRP was lost early in the arthropod evolution, being retained only in Chelicerata. Thus, one could assume that except of Chelicerata, RNA silencing does not employ RdRP-generated secondary siRNAs like those found in C. elegans.

Whether RdRP activity completely disappeared from RNAi in Drosophila (and those arthropods lacking an RdRP ortholog) is not completely understood but available data suggest that it is could the case. One should consider also the option that a missing RdRP ortholog in RNA silencing could be replaced by another RdRP, for example by horizontal transfer of some viral RdRP. In fact, there is a report of RdRP activity in Drosophila (Lipardi et al., 2001) but, was contradicted by experiments demonstrating the absence of transitive RNAi generating secondary sequences upstream of the region targeted by siRNAs (Roignant et al., 2003; Schwarz et al., 2002), so the issue remained unresolved. Later, dELP1, a non-canonical RdRP conserved in all eukaryotes, was suggested to associate with Dicer-2 and function as an RdRP (Lipardi and Paterson, 2009). However, the article was later retracted because the measured biochemical activity did not seem to be an authentic 
RdRP (Lipardi and Paterson, 2011). Taken together, as of now, there is no evidence for RdRP activity yielding secondary siRNAs and transitive RNAi in arthropod species lacking orthologs of ancestral RNA silencing-related RdRPs.

\section{miRNA-mediated control of gene expression}

miRNAs play physiologically important roles in arthropods, as suggested by phenotypes of mutants of miRNA pathway. The loss of Dicer-1 or Ago1 causes embryonic lethality (Lee et al., 2004; Pressman et al., 2012). Dicer-1 is also needed to maintain ovarian stem cells in Drosophila (Jin and Xie, 2007). Similarly, Ago1 is essential for oocyte formation and maintenance of germline stem cells in Drosophila (Azzam et al., 2012; Yang et al., 2007) and for locust oogenesis (Song et al., 2013). The miRNA pathway can also participate in response to physiological cues (Dekanty et al., 2010) or in regulation of immunity in arthropods, as shown for the Plasmodium infection mosquito (Winter et al., 2007). The miRNA pathway apparently expanded in pea aphid (insect, Hemiptera), whose genome contains four pasha, two dcr-1 and two ago2 paralogs, all of which are expressed and where one of the ago 1 paralogs shows signs of positive selection (Jaubert-Possamai et al., 2010). Notably, these expansions occurred concomitantly within a brief evolutionary period. it has been speculated that the miRNA pathway diversity could contribute to adapted phenotypes, which the pea aphid is able to produce from a single genotype (Jaubert-Possamai et al., 2010).

Drosophila's miRNA annotation in mirBase (Kozomara and Griffiths-Jones, 2014) is likely the most thoroughly done; it includes meta-analysis of $>10^{9}$ raw reads from 187 RNA-seq libraries comprising diverse developmental stages, specific tissue- and cell-types, mutant conditions, and/or Argonaute immunoprecipitations yielded a thorough annotation of miRNA loci, including definition of multiple phased by-products of cropping and dicing, abundant alternative 5' termini of certain miRNAs, frequent 3' untemplated additions, and potential editing events (Berezikov et al., 2011). Considering incomplete miRNA annotations in other species, miRBase numbers indicate that arthropods might have about one order of magnitude less miRNAs than mammals suggesting somewhat less expanded miRNA-mediated control of gene expression. In addition, there are only a few miRNAs conserved between Drosophila and mammals (the best known is Let-7 (Pasquinelli et al., 2000)).

Arthropods also employ non-canonical miRNAs. These include mirtrons that bypass Drosha processing (Martin et al., 2009; Okamura et al., 2007; Ruby et al., 2007). In addition, specific miRNA loops may accumulate as non-canonical miRNAs on AGO1 and mediate miRNA-type repression (Okamura et al., 2013). Another non-canonical miRNA was identified in rDNA arrays. Its processing requires Dicer-1 but not the Microprocessor complex and it is conserved among Diptera (Chak et al., 2015).

\section{RNAi pathway in arthropods}

Although Drosophila Dcr-2 or Ago-2 are nonessential and mutants can develop to adults with no strong phenotypes under standard laboratory conditions (Deshpande et al., 2005; 
miRNA size distribution in Drosophila.

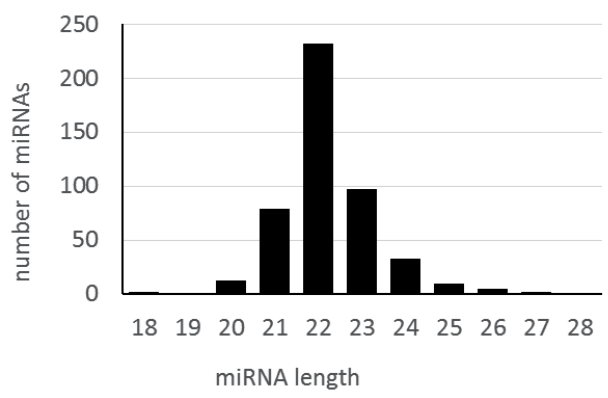

miRNA size distribution in Mus musculus

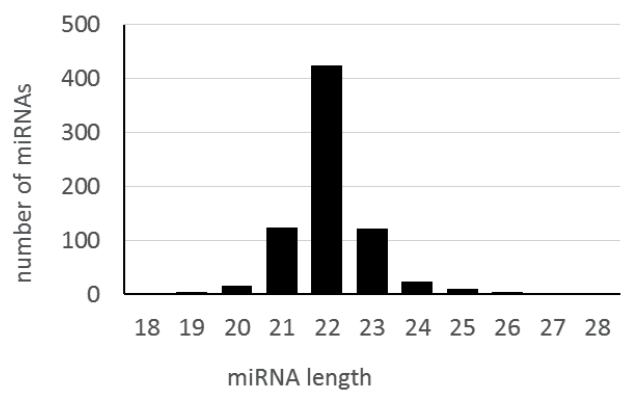

Figure 4 D. melanogaster miRNA lengths

The left graph depicts size distribution of all 466 miRNAs of a Drosophila melanogaster deposited in the miRBase (version 21). For comparison, the right graph shows size distribution of 721 high-confidence murine miRNAs.

Lee et al., 2004; Li et al., 2013; Xu et al., 2004), some minor phenotypes appear and severe defects in embryonic development have been noted in these mutants upon exposure to temperature perturbations (Deshpande et al., 2005; Li et al., 2013; Lucchetta et al., 2009).

RNAi is functional across other arthropods subphyla, including Chelicerata (ticks and mites (Hoy et al., 2016; Kurscheid et al., 2009; Schnettler et al., 2014)) and Crustacea (shrimps (Chen et al., 2011; Hoy et al., 2016; Huang and Zhang, 2013; Jariyapong et al., 2015; Maralit et al., 2015; Sabin and Cherry, 2013; Yang et al., 2014b). We did not find published functional RNAi data for Myriapoda but genomic analyses show that they have the necessary machinery (Palmer and Jiggins, 2015). In this section, we will discuss the role of antiviral RNAi and endo-siRNAs in Drosophila and arthropods in general.

\section{Antiviral RNAi}

RNAi plays a key role in innate immunity in arthropods and a large volume of the reviewed literature across the taxon dealt with antiviral role of RNAi. As it could be expected, most of the mechanistic data came from the Drosophila model.

The first evidence for antiviral RNAi in arthropods emerged in 2002 from a study that used flock house virus (FHV) is inducing RNAi (and is being targeted by RNAi) Drosophila host cells (Li et al., 2002). Infection of 14 different Drosophila RNA silencing mutants with a dsRNA X virus (DXV) showed that all but three lines were significantly more susceptible to viral infection (reduced survival and elevated viral titers) than normal flies. Moreover, replication of DXV was sequence-specifically inhibited (but not absolutely blocked) by „,immunizing“ Drosophila S2 cells with dsRNA from the coding region of DXV before infection (Zambon et al., 2006). Remarkably, increased susceptibility was observed not only for mutants of the RNAi pathway, such as $r 2 d 2$, armi, or ago2, but also for mutants of the piRNA pathway (aubergine and piwi), suggesting that RNAi is not the only RNA silencing pathway in Drosophila that can respond to a viral infection (Morazzani et al., 2012). The engagement of the piRNA pathway also extends to mosquitos (Leger et al., 
2013; Schnettler et al., 2013a; Vodovar et al., 2012). A number of studies provided ample mechanistic evidence that RNAi plays an essential role in antiviral response in Drosophila (Galiana-Arnoux et al., 2006; Nayak et al., 2010; van Rij et al., 2006; Wang et al., 2006).

The antiviral role of RNAi is conserved across the entire phylum. here, we will just list a few representative examples of taxons across arthropods with documented antiviral role of RNAi.

RNAi is an antiviral system in mosquitos, where RNAi also comes into contact also with viruses that infect humans, such as Dengue Virus Type 2 (Sanchez-Vargas et al., 2009), O'nyong-nyong virus (Keene et al., 2004), Sindbis virus (Adelman et al., 2012; Campbell et al., 2008), West Nile virus (Paradkar et al., 2012), Rift Valley Fever virus (Leger et al., 2013), Arbovirus (Schnettler et al., 2013b; van Cleef et al., 2014), Mosinovirus (Schuster et al., 2014), Culex Y virus (van Cleef et al., 2014). Importantly, viruses facing RNAi-based innate immunity evolve different RNAi inhibitors, proteins, which interfere with various stages of siRNA biogenesis. Such proteins have been identified in most of the aforementioned viruses. Needless to say that antiviral RNAi was reported also from other hexapods, such as silk moth (Liu et al., 2015; Zografidis et al., 2015). Antiviral RNAi was also reported for Chelicerata (ticks and mites (Hoy et al., 2016; Schnettler et al., 2014)) or Crustacea (shrimps (Hoy et al., 2016; Huang and Zhang, 2013; Jariyapong et al., 2015; Maralit et al., 2015; Sabin and Cherry, 2013; Yang et al., 2014b).

\section{Endogenous RNAi in the germline and soma}

Severe defects in embryonic development have been noted in Drosophila mutants lacking $D c r-2$ or $A g o 2$, exposed to temperature perturbations while these mutants otherwise develop under standard laboratory conditions to normal adults with no specific phenotype (Lucchetta et al., 2009). This indicated that one of the functions of endo-siRNA pathway is to stabilize embryonic development under environmental stress (Lucchetta et al., 2009). Subsequent analysis of the distinct phenotypes in RNAi-defective mutants (Deshpande et al., 2005; Li et al., 2013) and RNA-seq data lead to recognition of diversity of the endogenous RNAi pathway and various types of endo-siRNAs.

A substantial source of Drosophila endo-siRNAs comes from mobile elements (Chung et al., 2008; Czech et al., 2008; Ghildiyal et al., 2008; Kawamura et al., 2008; Okamura et al., 2008a). Endo-siRNAs in somatic tissues and cultured cells thus complement piRNAs that are responsible for genome surveillance predominantly in the germline. Importantly, as endo-siRNAs and piRNAs were found that originate from the same loci, it is possible that piRNA and endo-siRNA pathways might be interdependent in repression of mobile elements in Drosophila (Ghildiyal et al., 2008). The notion of interdependence in mobile element repression also resonates with above-mentioned piRNA contribution to antiviral defense.

Other endo-siRNAs map to protein-coding genes and potentially contribute to control of gene expression. Among them a significant portion maps to protein-coding regions (Czech et al., 2008; Ghildiyal et al., 2008; Kawamura et al., 2008; Okamura et al., 2008a; Okamura et al., 2008b). However, only endo-siRNAs derived from a small number of loci are produced in sufficient amount to reduce target mRNA levels, as exemplified by the esi-2 locus-derived endo-siRNAs targeting DNA damage-response gene Mus-308 (Czech et al., 2008). 
Table 1 Numbers of annotated miRNAs in selected arthropods in miRBase 22.1. Note: only species with >100 annotated miRNA precursors are shown for Hexapoda

\begin{tabular}{|l|l|c|c|}
\hline subphylum & species & $\begin{array}{c}\text { miRNA } \\
\text { precursors }\end{array}$ & $\begin{array}{c}\text { mature } \\
\text { miRNA }\end{array}$ \\
\hline Chelicerata & Ixodes scapularis & 49 & 49 \\
\hline & Rhipicephalus microplus & 24 & 24 \\
\hline & Tetranychus urticae & 52 & 92 \\
\hline Myriapoda & Strigamia maritima & 3 & 4 \\
\hline Crustacea & Daphnia pulex & 44 & 45 \\
\hline & Triops canciformis & 148 & 160 \\
\hline & Aedes aegypti & 122 & 164 \\
\hline & Apis mellifera & 254 & 262 \\
\hline & Acyrthosiphon pisum & 123 & 97 \\
\hline & Bombyx mori & 487 & 469 \\
\hline & Drosophila melanogaster & 258 & 213 \\
\hline & Drosophila simulans & 148 & 328 \\
\hline & Drosophila virilis & 180 & 127 \\
\hline & Plutella xylostella & 133 & 590 \\
\hline & Tribolium castaneum & 342 & \\
\hline
\end{tabular}

Another type of Drosophila endo-siRNAs arises from overlapping antisense transcripts observed in hundreds of protein-coding loci (Okamura et al., 2008a). Abundance of such endo-siRNAs is generally low. Potential mRNA targets of such endo-siRNAs are not upregulated in Ago2-deficient flies, suggesting that these endo-siRNAs are not involved in posttranscriptional control of mRNA levels under physiological conditions (Czech et al., 2008). Interestingly, a dsRNA/endo-siRNA-binding protein Blanks, which associates with DCR-2 and forms an alternative Argonaute-independent functional RISC complex, has a role in spermatogenesis (Gerbasi et al., 2011). As Blanks deletion does not affect transposon activity, this finding suggests a role for endo-siRNAs in regulation of protein-coding mRNAs in Drosophila sperm development.

Yet another distinct type of endo-siRNAs are those derived from hairpin RNAs, whose biogenesis involves HEN1, canonical RNAi factors Dicer-2 and AGO2 plus miRNA factor Loquacious (Okamura et al., 2008c), specifically the LOQS-PD isoform(Zhou et al., 2009). One of the roles of hairpin RNA-derived endo-siRNAs is regulation of gene expression (Wen et al., 2015).

\section{Systemic RNAi}

Some insects, such as red flour beetle Tribalism, have efficient systemic RNAi where injection of adults causes RNAi effects in the progeny (Bucher et al., 2002; Tomoyasu et al., 2008). One of the well-known systemic RNAi factors is SID-1, a transmembrane protein transporting dsRNA across cell boundaries, which was first identified in C. elegans 
(Feinberg and Hunter, 2003). Ectopic expression of SID-1 is sufficient for permitting a systemic RNAi through dsRNA soaking in insect cells (Feinberg and Hunter, 2003; Mon et al., 2013; Shih and Hunter, 2011).

Non-cell autonomous RNAi exists across arthropods where different taxa have different numbers of sid-1 homologs. Importantly, some taxons lack systemic RNAi, which is not necessarily accompanied with the absence of sid-1 homologs; systemic RNAi can also be developmentally restricted or simply inefficient despite the expression of sid-1 homologs (Tomoyasu et al., 2008). Importantly, SID-1 is not the only system of systemic RNAi as was demonstrated in the locust model (Luo et al., 2012) or in Tribalism (Bucher et al., 2002; Tomoyasu et al., 2008).

There is a number of insect species, in which was found systemic RNAi or at least sid-1 homologs, include the aforementioned red flour beetle, Colorado potato beetle (Cappelle et al., 2016), juvenile grasshopper (Dong and Friedrich, 2005), brown planthopper (Xu et al., 2013), oriental leaf worm moth (Gong et al., 2015), diamondback moth (Wang et al., 2014), silk moth (Tomoyasu et al., 2008), honeybee (Honeybee Genome Sequencing, 2006), soybean aphid (Bansal and Michel, 2013), cotton/melon aphid (Xu and Han, 2008), grain aphid (Xu and Han, 2008). Beyond Hexapoda, there was also one report of sid-1 homolog in Crustacea (shrimp) (Labreuche et al., 2010; Maralit et al., 2015).

Sid-like genes were not found in Drosophila (Roignant et al., 2003), Hessian fly (Shreve et al., 2013), or mosquito Anopheles gambiae (Blandin et al., 2002). However, it should be kept in mind that this is not a conclusive evidence for absence of non-cell autonomous RNAi. For example, non-cell autonomous RNAi could be experimentally achieved also in Drosophila (Dzitoyeva et al., 2003) and it has been proposed that it would have a natural role in conjunction with antiviral RNAi in adult flies (Saleh et al., 2009).

\section{Dicer-dependent nuclear silencing}

Small RNAs in plants and fungi can mediate transcriptional silencing via chromatin remodelling/DNA methylation. A nuclear role and chromatin remodelling has been also attributed to the PIWI-loaded piRNA class of small RNAs protecting genome integrity in the germline. The role of Dicer-dependent small RNAs in transcriptional silencing in Metazoa is poorly understood and, in some cases, controversial. In any case, studies in Drosophila yielded some, albeit heterogeneous, evidence connecting Dicer-dependent small RNAs with transcriptional silencing and chromatin changes.

The best known small RNA-dependent transcriptional silencing mechanism is the piRNA pathway, which controls transcriptional silencing of retrotransposons (reviewed in $\mathrm{Fu}$ and Wang, 2014; Haase, 2016; Han and Zamore, 2014; Sato and Siomi, 2013). We do not cover the piRNA pathway as it is neither miRNA nor RNAi; piRNAs are not produced from a dsRNA but from complementary single-stranded transcripts through a concerted action of multiple factors. In any case, the piRNA pathway occasionally intersects with RNAi and miRNA pathways. For instance, it was shown that a functional miRNA pathway is required for the piRNA-mediated transcriptional silencing of mobile elements (Mugat et al., 2015). The mechanistic link seems to be provided by two specific miRNAs, miR-14 and miR-34 
(Mugat et al., 2015). This highlights the issue of discerning miRNA-mediated effects on chromatin and direct chromatin regulation by small RNAs.

A possible existence of transcriptional silencing mediated by Dicer-dependent small RNAs emerged from several analyses. First, it was found that AGO1 is found in the nucleus and cytosol in early embryos and that repeat induced silencing and transcriptional co-suppression were disrupted by Ago-1 mutation (Pushpavalli et al., 2012). The effect was accompanied by reduced H3K9me2 and H3K27me3 histone modifications (Pushpavalli et al., 2012). However, it is not clear whether this phenomenon is caused by a direct endo-siRNA-mediated heterochromatin induction or an indirect effect of miRNAs (similarly to the situation mentioned in the previous paragraph). Another possible bridge between the miRNA pathway and transcriptional regulation is Glioma amplified sequence41 (Gas41), a chromatin remodeler, implicated in repeat-induced transgene silencing, which also interacts with Dicer-1 (Gandhi et al., 2015). Others proposed that AGO1 (and Dicer-2) interacts with RNA pol II and contribute to heterochromatin formation (Kavi and Birchler, 2009).

AGO2 has been implicated in alternative splicing and transcriptional silencing, which included Polycomb group complex (associated with H3K27 methylation) (Taliaferro et al., 2013). Again, it is not clear how direct and indirect mechanism is responsible for the observed effects. RNAi machinery is not certainly an essential component of polycomb-mediated silencing as it was demonstrated that RNAi pathway is dispensable for the polycomb-mediated silencing of the homeotic Bithorax Complex (Cernilogar et al., 2013). $\mathrm{AGO} 2$ was also implicated in chromatin insulator function that would be independent of RNAi (Moshkovich et al., 2011). AGO2 was localized by chromatin immunoprecipitation to euchromatin but not heterochromatin and co-localized and physically interacted with CTCF/CP190 chromatin insulators (Moshkovich et al., 2011). AGO2, together with Dicer-2 and R2D2 was implicated in H3K9 methylation, suggesting that endo-siRNAs might regulate heterochromatin (Fagegaltier et al., 2009). A possible bridge between RNA silencing and chromatin could be VIG, the aforementioned RISC component (Gracheva et al., 2009). Chromatin-related factors also emerged from screens for RNAi and miRNA genes (Ghosh et al., 2014; Pressman et al., 2012).

Taken together, despite a relatively large volume of evidence, there is still not a consensus and a validated model explaining how would miRNAs or endo-siRNAs guide chromatin remodelling in Drosophila (or in arthropods in general).

\section{Other dsRNA response pathways in arthropods}

While RNAi is an important antiviral innate immunity mechanism in arthropods, it should be pointed out that it is not the only one and that the innate immunity of arthropods is much more complex. A study of five chelicerates, a myriapod, and a crustacean revealed traces of an ancient origin of innate immunity, with some arthropods having Toll-like receptors and $\mathrm{C} 3$-complement factors that are more closely related in sequence or structure to vertebrates than other arthropods (Palmer and Jiggins, 2015). Thus, apart from a robust and sequence-specific RNAi, arthropods also have a largely unexplored potential 
to mount a sequence-independent response to dsRNA (reviewed in Wang et al., 2015a). Such sequence-independent response would, for example, explain increased expression of apoptosis-related genes 24 hours upon exposing shrimps to encapsulated dsRNA (Jariyapong et al., 2015).In fact, shrimp has several interferon system-related genes such as dsRNA-dependent protein kinase PKR and Toll-like receptor 3, which are induced upon dsRNA exposure (Wang et al., 2013). Furthermore, Crustacea have many genes homologous to genes of the vertebrate interferon response suggesting that they might combine sequence-specific and sequence-independent innate immunity response to nucleic acids (Wang et al., 2013).

\section{$A D A R$}

Similarly to all previously discussed model systems, Drosophila (and presumably all arthropods) have A-to-I editing system. Drosophila has a single ADAR related to vertebrate ADAR2 (Barraud et al., 2012). ADAR is developmentally regulated and essential gene (Palladino et al., 2000). Drosophila ADAR edits convergent transcripts (Peters et al., 2003), antisense read-through transcripts of KP elements (Peters et al., 2003) as well as miRNAs (Chawla and Sokol, 2014). Drosophila ADAR edit primary microRNA (pri-miRNA) transcripts to alter the structural conformation of these precursors resulting in positive or negative modulation of miRNA expression or its activity (Chawla and Sokol, 2014; Cui et al., 2015). Despite its biochemical activity would imply it, there is no good evidence to show that ADAR antagonizes RNAi in Drosophila (Paro et al., 2012).

\section{Summary}

Taken together, arthropods are an extremely large and diverse taxon, characterized by an extended genetic separation of miRNA and RNAi pathways (Fig. 5). The separation is not complete and structure of small RNAs appearing in the system strongly influences their sorting onto AGO proteins. The main arthropod model system - Drosophila - lost the RdRP component of RNA silencing, which seems to be also the case for Hexapoda, Crustacea and Myriapoda but not Chelicerata.

\section{Acknowledgement}

I would like to thank my colleagues Jan Paces, Miloslav Nic, and Tomas Novotny for help with collecting literature for the review and Eliska Svobodova for help with phylogenetic analysis of Dicer. The review content was produced under a contract OC/ EFSA/GMO/2015/01-CT 01 with European Food Safety Authority (EFSA); the opinions expressed are those of the contractor only and do not represent EFSA's official position. Publication of the review was funded by LO1220 and LM2015063 by the Ministry of Education, Youth and Sports. 

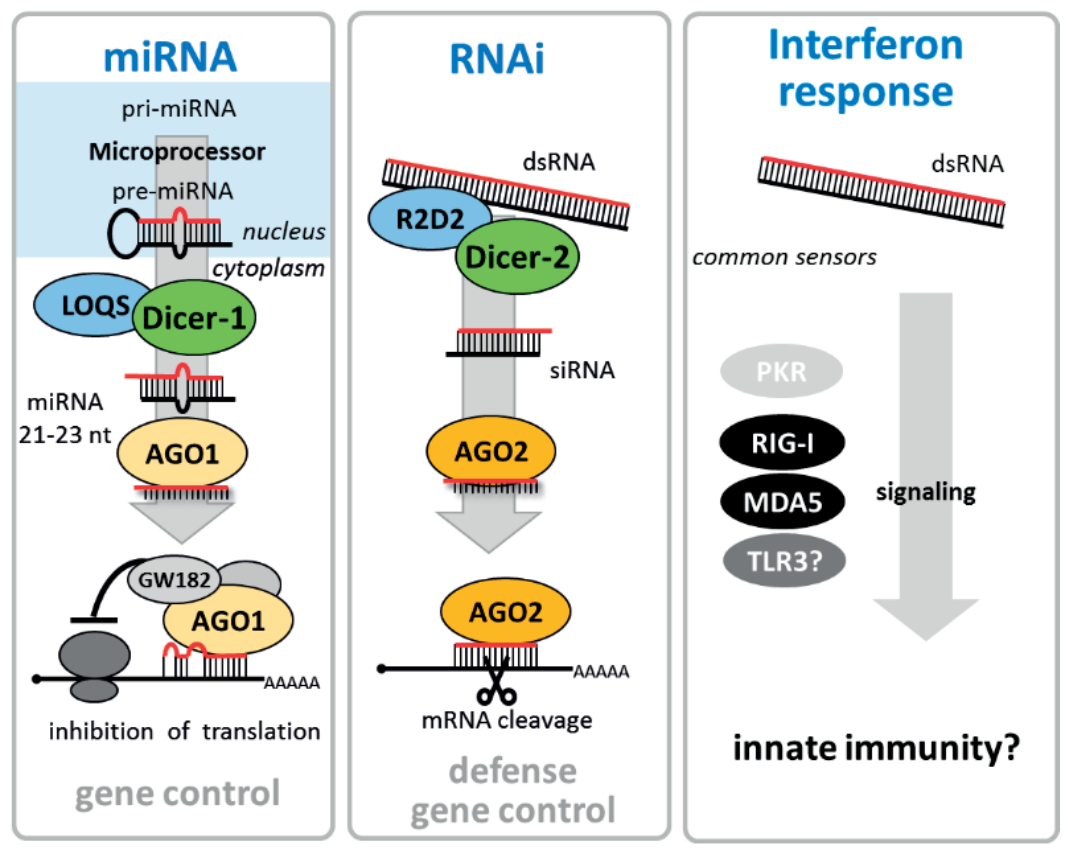

Figure 5 Overview of discussed arthropod pathways dsRNA and miRNA pathways in Arthropoda show separation of miRNA and RNAi pathways, each utilizing a more-or-less dedicated set of proteins for small RNA biogenesis and effector complex.

\section{References}

Abe, M., Naqvi, A., Hendriks, G.J., Feltzin, V., Zhu, Y.Q., Grigoriev, A., and Bonini, N.M. (2014). Impact of age-associated increase in 2 '-O-methylation of miRNAs on aging and neurodegeneration in Drosophila. Genes \& Development 28, 44-57.

Adelman, Z.N., Anderson, M.A.E., Liu, M., Zhang, L., and Myles, K.M. (2012). Sindbis virus induces the production of a novel class of endogenous siRNAs in Aedes aegypti mosquitoes. Insect Molecular Biology 21, 357-368.

Ameres, S.L., Horwich, M.D., Hung, J.H., Xu, J., Ghildiyal, M., Weng, Z.P., and Zamore, P.D. (2010). Target RNA-Directed Trimming and Tailing of Small Silencing RNAs. Science 328, 1534-1539.

Antic, S., Wolfinger, M.T., Skucha, A., Hosiner, S., and Dorner, S. (2015). General and MicroRNA-Mediated mRNA Degradation Occurs on Ribosome Complexes in Drosophila Cells. Molecular and Cellular Biology 35, 2309-2320.

Azzam, G., Smibert, P., Lai, E.C., and Liu, J.L. (2012). Drosophila Argonaute 1 and its miRNA biogenesis partners are required for oocyte formation and germline cell division. Developmental Biology 365, 384-394.

Bansal, R., and Michel, A.P. (2013). Core RNAi Machinery and Sid1, a Component for Systemic RNAi, in the Hemipteran Insect, Aphis glycines. International Journal of Molecular Sciences 14, 3786-3801. 
Barraud, P., Heale, B.S.E., O’Connell, M.A., and Allain, F.H.T. (2012). Solution structure of the N-terminal dsRBD of Drosophila ADAR and interaction studies with RNA. Biochimie 94, 1499-1509. Bartel, D.P. (2018). Metazoan MicroRNAs. Cell 173, 20-51.

Behm-Ansmant, I., Rehwinkel, J., Doerks, T., Stark, A., Bork, P., and Izaurralde, E. (2006). MRNA degradation by miRNAs and GW182 requires both CCR4 : NOT deadenylase and DCP1 : DCP2 decapping complexes. Genes \& Development 20, 1885-1898.

Berezikov, E., Robine, N., Samsonova, A., Westholm, J.O., Naqvi, A., Hung, J.H., Okamura, K., Dai, Q., Bortolamiol-Becet, D., Martin, R., et al. (2011). Deep annotation of Drosophila melanogaster microRNAs yields insights into their processing, modification, and emergence. Genome Research 21, 203-215.

Bernhardt, S.A., Simmons, M.P., Olson, K.E., Beaty, B.J., Blair, C.D., and Black, W.C. (2012). Rapid Intraspecific Evolution of miRNA and siRNA Genes in the Mosquito Aedes aegypti. Plos One 7, e44198-e44198.

Bernstein, E., Caudy, A.A., Hammond, S.M., and Hannon, G.J. (2001). Role for a bidentate ribonuclease in the initiation step of RNA interference. Nature 409, 363-366.

Blandin, S., Moita, L.F., Kocher, T., Wilm, M., Kafatos, F.C., and Levashina, E.A. (2002). Reverse genetics in the mosquito Anopheles gambiae: targeted disruption of the Defensin gene. EMBO Rep 3, 852-856.

Bozzetti, M.P., Specchia, V., Cattenoz, P.B., Laneve, P., Geusa, A., Sahin, H.B., Di Tommaso, S., Friscini, A., Massari, S., Diebold, C., et al. (2015). The Drosophila fragile X mental retardation protein participates in the piRNA pathway. Journal of Cell Science 128, 2070-2084.

Bucher, G., Scholten, J., and Klingler, M. (2002). Parental RNAi in Tribolium (Coleoptera). Curr Biol 12, R85-86.

Burroughs, A.M., Ando, Y., de Hoon, M.J.L., Tomaru, Y., Nishibu, T., Ukekawa, R., Funakoshi, T., Kurokawa, T., Suzuki, H., Hayashizaki, Y., et al. (2010). A comprehensive survey of 3 ' animal miRNA modification events and a possible role for 3 ' adenylation in modulating miRNA targeting effectiveness. Genome Research 20, 1398-1410.

Campbell, C.L., Keene, K.M., Brackney, D.E., Olson, K.E., Blair, C.D., Wilusz, J., and Foy, B.D. (2008). Aedes aegypti uses RNA interference in defense against Sindbis virus infection. BMC Microbiology 8, 47-47.

Cappelle, K., de Oliveira, C.F., Van Eynde, B., Christiaens, O., and Smagghe, G. (2016). The involvement of clathrin-mediated endocytosis and two Sid-1-like transmembrane proteins in double-stranded RNA uptake in the Colorado potato beetle midgut. Insect molecular biology.

Caudy, A.A., Ketting, R.F., Hammond, S.M., Denli, A.M., Bathoorn, A.M.P., Tops, B.B.J., Silva, J.M., Myers, M.M., Hannon, G.J., and Plasterk, R.H.A. (2003). A micrococcal nuclease homologue in RNAi effector complexes. Nature 425, 411-414.

Caudy, A.A., Myers, M., Hannon, G.J., and Hammond, S.M. (2002). Fragile X-related protein and VIG associate with the RNA interference machinery. Genes \& Development 16, 2491-2496.

Cenik, E.S., Fukunaga, R., Lu, G., Dutcher, R., Wang, Y.M., Hall, T.M.T., and Zamore, P.D. (2011). Phosphate and R2D2 Restrict the Substrate Specificity of Dicer-2, an ATP-Driven Ribonuclease. Molecular Cell 42, 172-184.

Cernilogar, F.M., Burroughs, A.M., Lanzuolo, C., Breiling, A., Imhof, A., and Orlando, V. (2013). RNA-Interference Components Are Dispensable for Transcriptional Silencing of the Drosophila Bithorax-Complex. Plos One 8, e65740-e65740. 
Cerutti, H., and Casas-Mollano, J.A. (2006). On the origin and functions of RNA-mediated silencing: from protists to man. Current genetics 50, 81-99.

Chak, L.L., Mohammed, J., Lai, E.C., Tucker-Kellogg, G., and Okamura, K. (2015). A deeply conserved, noncanonical miRNA hosted by ribosomal DNA. RNA 21, 375-384.

Chawla, G., and Sokol, N.S. (2014). ADAR mediates differential expression of polycistronic microRNAs. Nucleic Acids Research 42, 5245-5255.

Chekulaeva, M., Filipowicz, W., and Parker, R. (2009). Multiple independent domains of dGW182 function in miRNA-mediated repression in Drosophila. RNA 15, 794-803.

Chekulaeva, M., Mathys, H., Zipprich, J.T., Attig, J., Colic, M., Parker, R., and Filipowicz, W. (2011). miRNA repression involves GW182-mediated recruitment of CCR4-NOT through conserved W-containing motifs. Nature Structural \& Molecular Biology 18, 1218-U1262.

Chekulaeva, M., Parker, R., and Filipowicz, W. (2010). The GW/WG repeats of Drosophila GW182 function as effector motifs for miRNA-mediated repression. Nucleic Acids Research 38, 6673-6683.

Chen, Y.H., Jia, X.T., Zhao, L., Li, C.Z., Zhang, S.A., Chen, Y.G., Weng, S.P., and He, J.G. (2011). Identification and functional characterization of Dicer2 and five single VWC domain proteins of Litopenaeus vannamei. Developmental and Comparative Immunology 35, 661-671.

Chen, Y.H., Zhao, L., Jia, X.T., Li, X.Y., Li, C.Z., Yan, H., Weng, S.P., and He, J.G. (2012). Isolation and characterization of cDNAs encoding Ars2 and Pasha homologues, two components of the RNA interference pathway in Litopenaeus vannamei. Fish \& Shellfish Immunology 32, 373-380.

Chung, W.J., Okamura, K., Martin, R., and Lai, E.C. (2008). Endogenous RNA interference provides a somatic Defense against Drosophila transposons. Current Biology 18, 795-802.

Cui, Y.L., Huang, T.Z., and Zhang, X.B. (2015). RNA editing of microRNA prevents RNA-induced silencing complex recognition of target mRNA. Open Biology 5, 150126-150126.

Czech, B., Malone, C.D., Zhou, R., Stark, A., Schlingeheyde, C., Dus, M., Perrimon, N., Kellis, M., Wohlschlegel, J.A., Sachidanandam, R., et al. (2008). An endogenous small interfering RNA pathway in Drosophila. Nature 453, 798-U797.

Czech, B., Zhou, R., Erlich, Y., Brennecke, J., Binari, R., Villalta, C., Gordon, A., Perrimon, N., and Hannon, G.J. (2009). Hierarchical Rules for Argonaute Loading in Drosophila. Molecular Cell 36, 445-456.

Dechklar, M., Udomkit, A., and Panyim, S. (2008). Characterization of Argonaute cDNA from Penaeus monodon and implication of its role in RNA interference. Biochem Biophys Res Commun 367, 768-774.

Dekanty, A., Romero, N.M., Bertolin, A.P., Thomas, M.G., Leishman, C.C., Perez-Perri, J.I., Boccaccio, G.L., and Wappner, P. (2010). Drosophila Genome-Wide RNAi Screen Identifies Multiple Regulators of HIF-Dependent Transcription in Hypoxia. Plos Genetics 6, e1000994-e1000994.

Denli, A.M., Tops, B.B.J., Plasterk, R.H.A., Ketting, R.F., and Hannon, G.J. (2004). Processing of primary microRNAs by the Microprocessor complex. Nature 432, 231-235.

Deshpande, G., Calhoun, G., and Schedl, P. (2005). Drosophila argonaute-2 is required early in embryogenesis for the assembly of centric/centromeric heterochromatin, nuclear division, nuclear migration, and germ-cell formation. Genes \& Development 19, 1680-1685.

Dong, Y., and Friedrich, M. (2005). Nymphal RNAi: systemic RNAi mediated gene knockdown in juvenile grasshopper. BMC Biotechnology 5, 25-25.

Dzitoyeva, S., Dimitrijevic, N., and Manev, H. (2003). Gamma-aminobutyric acid B receptor 1 mediates behavior-impairing actions of alcohol in Drosophila: adult RNA interference and 
pharmacological evidence. Proceedings of the National Academy of Sciences of the United States of America 100, 5485-5490.

Eulalio, A., Huntzinger, E., and Izaurralde, E. (2008). GW182 interaction with Argonaute is essential for miRNA-mediated translational repression and mRNA decay. Nature Structural \& Molecular Biology 15, 346-353.

Eulalio, A., Tritschler, F., Buettner, R., Weichenrieder, O., Izaurralde, E., and Truffault, V. (2009). The RRM domain in GW182 proteins contributes to miRNA-mediated gene silencing. Nucleic Acids Research 37, 2974-2983.

Fagegaltier, D., Bouge, A.L., Berry, B., Poisot, E., Sismeiro, O., Coppee, J.Y., Theodore, L., Voinnet, O., and Antoniewski, C. (2009). The endogenous siRNA pathway is involved in heterochromatin formation in Drosophila. Proceedings of the National Academy of Sciences of the United States of America 106, 21258-21263.

Feinberg, E.H., and Hunter, C.P. (2003). Transport of dsRNA into cells by the transmembrane protein SID-1. Science 301, 1545-1547.

Feltzin, V.L., Khaladkar, M., Abe, M., Parisi, M., Hendriks, G.J., Kim, J., and Bonini, N.M. (2015). The exonuclease Nibbler regulates age-associated traits and modulates piRNA length in Drosophila. Aging Cell 14, 443-452.

Filippov, V., Solovyev, V., Filippova, M., and Gill, S.S. (2000). A novel type of RNase III family proteins in eukaryotes. Gene 245, 213-221.

Flynt, A.S., Greimann, J.C., Chung, W.J., Lima, C.D., and Lai, E.C. (2010). MicroRNA Biogenesis via Splicing and Exosome-Mediated Trimming in Drosophila. Molecular Cell 38, 900-907.

Forstemann, K., Horwich, M.D., Wee, L., Tomari, Y., and Zamore, P.D. (2007). Drosophila microRNAs are sorted into functionally distinct argonaute complexes after production by Dicer-1. Cell 130, 287-297.

Forstemann, K., Tomari, Y., Du, T.T., Vagin, V.V., Denli, A.M., Bratu, D.P., Klattenhoff, C., Theurkauf, W.E., and Zamore, P.D. (2005). Normal microRNA maturation and germ-line stem cell maintenance requires loquacious, a double-stranded RNA-binding domain protein. Plos Biology 3, 1187-1201.

$\mathrm{Fu}$, Q., and Wang, P.J. (2014). Mammalian piRNAs: Biogenesis, function, and mysteries. Spermatogenesis 4, e27889-e27889.

Fukaya, T., Iwakawa, H.-o., and Tomari, Y. (2014). MicroRNAs Block Assembly of eIF4F Translation Initiation Complex in Drosophila. Molecular Cell 56, 67-78.

Fukaya, T., and Tomari, Y. (2011). PABP is not essential for microRNA-mediated translational repression and deadenylation in vitro. EMBO J 30, 4998-5009.

Fukunaga, R., Colpan, C., Han, B.W., and Zamore, P.D. (2014). Inorganic phosphate blocks binding of pre-miRNA to Dicer-2 via its PAZ domain. EMBO J 33, 371-384.

Fukunaga, R., Han, B.W., Hung, J.H., Xu, J., Weng, Z.P., and Zamore, P.D. (2012). Dicer Partner Proteins Tune the Length of Mature miRNAs in Flies and Mammals. Cell 151, 533-546.

Galiana-Arnoux, D., Dostert, C., Schneemann, A., Hoffmann, J.A., and Imler, J.L. (2006). Essential function in vivo for Dicer-2 in host defense against RNA viruses in drosophila. Nature Immunology 7, 590-597.

Gandhi, S.G., Bag, I., Sengupta, S., Pal-Bhadra, M., and Bhadra, U. (2015). Drosophila oncogene Gas41 is an RNA interference modulator that intersects heterochromatin and the small interfering RNA pathway. Febs Journal 282, 153-173. 
Gerbasi, V.R., Preall, J.B., Golden, D.E., Powell, D.W., Cummins, T.D., and Sontheimer, E.J. (2011). Blanks, a nuclear siRNA/dsRNA-binding complex component, is required for Drosophila spermiogenesis. Proceedings of the National Academy of Sciences of the United States of America 108, 3204-3209.

Ghildiyal, M., Seitz, H., Horwich, M.D., Li, C.J., Du, T.T., Lee, S., Xu, J., Kittler, E.L.W., Zapp, M.L., Weng, Z.P., et al. (2008). Endogenous siRNAs derived from transposons and mRNAs in Drosophila somatic cells. Science 320, 1077-1081.

Ghildiyal, M., Xu, J., Seitz, H., Weng, Z.P., and Zamore, P.D. (2010). Sorting of Drosophila small silencing RNAs partitions microRNA* strands into the RNA interference pathway. RNA 16, 43-56.

Ghosh, S., Kakumani, P.K., Kumar, A., Malhotra, P., Mukherjee, S.K., and Bhatnagar, R.K. (2014). Genome wide screening of RNAi factors of Sf21 cells reveal several novel pathway associated proteins. BMC Genomics 15, 775-775.

Gomez-Orte, E., and Belles, X. (2009). MicroRNA-dependent metamorphosis in hemimetabolan insects. Proceedings of the National Academy of Sciences of the United States of America 106, 21678-21682.

Gong, L., Wang, Z., Wang, H., Qi, J., Hu, M., and Hu, Q. (2015). Core RNAi machinery and three Sid-1 related genes in Spodoptera litura (Fabricius). International Journal of Agriculture and Biology 17, 937-944.

Gracheva, E., Dus, M., and Elgin, S.C.R. (2009). Drosophila RISC Component VIG and Its Homolog Vig2 Impact Heterochromatin Formation. Plos One 4, e6182-e6182.

Haac, M.E., Anderson, M.A.E., Eggleston, H., Myles, K.M., and Adelman, Z.N. (2015). The hub protein loquacious connects the microRNA and short interfering RNA pathways in mosquitoes. Nucleic Acids Research 43, 3688-3700.

Haase, A.D. (2016). A Small RNA-Based Immune System Defends Germ Cells against Mobile Genetic Elements. Stem Cells International 2016, 7595791-7595791.

Han, B.W., Hung, J.H., Weng, Z.P., Zamore, P.D., and Ameres, S.L. (2011). The 3 '-to-5 ' Exoribonuclease Nibbler Shapes the 3 ' Ends of MicroRNAs Bound to Drosophila Argonaute1. Current Biology 21, 1878-1887.

Han, B.W., and Zamore, P.D. (2014). PiRNAs. Current Biology 24, R730-R733.

Hartig, J.V., Esslinger, S., Bottcher, R., Saito, K., and Forstemann, K. (2009). Endo-siRNAs depend on a new isoform of loquacious and target artificially introduced, high-copy sequences. EMBO J $28,2932-2944$.

Hartig, J.V., and Forstemann, K. (2011). Loqs-PD and R2D2 define independent pathways for RISC generation in Drosophila. Nucleic Acids Research 39, 3836-3851.

He, Y.D., and Zhang, X.B. (2012). Comprehensive characterization of viral miRNAs involved in white spot syndrome virus (WSSV) infection. RNA Biology 9, 1019-1029.

Herbert, K.M., Pimienta, G., DeGregorio, S.J., Alexandrov, A., and Steitz, J.A. (2013). Phosphorylation of DGCR8 Increases Its Intracellular Stability and Induces a Progrowth miRNA Profile. Cell Reports 5, 1070-1081.

Honeybee Genome Sequencing, C. (2006). Insights into social insects from the genome of the honeybee Apis mellifera. Nature 443, 931-949.

Horwich, M.D., Li, C.J., Matranga, C., Vagin, V., Farley, G., Wang, P., and Zamore, P.D. (2007). The Drosophila RNA methyltransferase, DmHen1, modifies germline piRNAs and single-stranded siRNAs in RISC. Current Biology 17, 1265-1272. 
Hoy, M.A., Waterhouse, R.M., Wu, K., Estep, A.S., Ioannidis, P., Palmer, W.J., Pomerantz, A.F., Simao, F.A., Thomas, J., Jiggins, F.M., et al. (2016). Genome sequencing of the phytoseiid predatory mite Metaseiulus occidentalis reveals completely atomised Hox genes and super-dynamic intron evolution. Genome biology and evolution.

Huang, H.D., Li, Y.J., Szulwach, K.E., Zhang, G.Q., Jin, P., and Chen, D.H. (2014). AGO3 Slicer activity regulates mitochondria-nuage localization of Armitage and piRNA amplification. Journal of Cell Biology 206, 217-230.

Huang, T.Z., Xu, D.D., and Zhang, X.B. (2012). Characterization of shrimp Drosha in virus infection. Fish \& Shellfish Immunology 33, 575-581.

Huang, T.Z., and Zhang, X.B. (2013). Host defense against DNA virus infection in shrimp is mediated by the siRNA pathway. European Journal of Immunology 43, 137-146.

Huntzinger, E., Braun, J.E., Heimstaedt, S., Zekri, L., and Izaurralde, E. (2010). Two PABPC1-binding sites in GW182 proteins promote miRNA-mediated gene silencing. EMBO J 29, 4146-4160.

Huntzinger, E., Kuzuoglu-Oeztuerk, D., Braun, J.E., Eulalio, A., Wohlbold, L., and Izaurralde, E. (2013). The interactions of GW182 proteins with PABP and deadenylases are required for both translational repression and degradation of miRNA targets. Nucleic Acids Research 41, 978-994.

Ishizuka, A., Siomi, M.C., and Siomi, H. (2002). A Drosophila fragile X protein interacts with components of RNAi and ribosomal proteins. Genes \& Development 16, 2497-2508.

Iwasaki, S., Kawamata, T., and Tomari, Y. (2009). Drosophila Argonaute1 and Argonaute2 Employ Distinct Mechanisms for Translational Repression. Molecular Cell 34, 58-67.

Iwasaki, S., Sasaki, H.M., Sakaguchi, Y., Suzuki, T., Tadakuma, H., and Tomari, Y. (2015). Defining fundamental steps in the assembly of the Drosophila RNAi enzyme complex. Nature 521, 533-U274.

Jariyapong, P., Weerachatyanukul, W., Direkbusarakom, S., Hirono, I., Wuthisuthimethavee, S., and Chotwiwatthanakun, C. (2015). Enhancement of shrimp immunity against white spot syndrome virus by Macrobrachium rosenbergii nodavirus-like particle encapsulated VP28 double-stranded RNA. Aquaculture 446, 325-332.

Jaskiewicz, L., and Filipowicz, W. (2008). Role of Dicer in posttranscriptional RNA silencing. Current topics in microbiology and immunology 320, 77-97.

Jaubert-Possamai, S., Rispe, C., Tanguy, S., Gordon, K., Walsh, T., Edwards, O., and Tagu, D. (2010). Expansion of the miRNA Pathway in the Hemipteran Insect Acyrthosiphon pisum. Molecular Biology and Evolution 27, 979-987.

Jiang, F., Ye, X.C., Liu, X., Fincher, L., McKearin, D., and Liu, Q.H. (2005). Dicer-1 and R3D1-L catalyze microRNA maturation in Drosophila. Genes \& Development 19, 1674-1679.

Jiang, F.F., Lu, F.L., Li, P.X., Liu, W., Zhao, L., Wang, Q.F., Cao, X.F., Zhang, L., and Zhang, Y.Q. (2016). Drosophila Homolog of FMRP Maintains Genome Integrity by Interacting with Piwi. Journal of Genetics and Genomics 43, 11-24.

Jin, Z.G., and Xie, T. (2007). Dcr-1 maintains Drosophila ovarian stem cells. Current Biology 17, 539-544.

Kadener, S., Rodriguez, J., Abruzzi, K.C., Khodor, Y.L., Sugino, K., Marr, M.T., Nelson, S., and Rosbash, M. (2009). Genome-wide identification of targets of the drosha-pasha/DGCR8 complex. RNA 15, 537-545.

Kavi, H.H., and Birchler, J.A. (2009). Interaction of RNA polymerase II and the small RNA machinery affects heterochromatic silencing in Drosophila. Epigenetics \& Chromatin 2, 15-15. 
Kawamata, T., Seitz, H., and Tomari, Y. (2009). Structural determinants of miRNAs for RISC loading and slicer-independent unwinding. Nature Structural \& Molecular Biology 16, 953-U977.

Kawamura, Y., Saito, K., Kin, T., Ono, Y., Asai, K., Sunohara, T., Okada, T.N., Siomi, M.C., and Siomi, H. (2008). Drosophila endogenous small RNAs bind to Argonaute 2 in somatic cells. Nature 453, 793-U795.

Keene, K.M., Foy, B.D., Sanchez-Vargas, I., Beaty, B.J., Blair, C.D., and Olson, K.E. (2004). RNA interference acts as a natural antiviral response to O'nyong-nyong virus (Alphavirus; Togaviridae) infection of Anopheles gambiae. Proceedings of the National Academy of Sciences of the United States of America 101, 17240-17245.

Kim, K., Lee, Y.S., and Carthew, R.W. (2007). Conversion of pre-RISC to holo-RISC by Ago2 during assembly of RNAi complexes. RNA 13, 22-29.

Kim, K., Lee, Y.S., Harris, D., Nakahara, K., and Carthew, R.W. (2006). The RNAi pathway initiated by Dicer-2 in Drosophila. Cold Spring Harbor Symposia on Quantitative Biology 71, 39-44.

Kolliopoulou, A., and Swevers, L. (2013). Functional analysis of the RNAi response in ovary-derived silkmoth Bm5 cells. Insect Biochemistry and Molecular Biology 43, 654-663.

Kozomara, A., and Griffiths-Jones, S. (2014). miRBase: annotating high confidence microRNAs using deep sequencing data. Nucleic Acids Res 42, D68-73.

Ku, H.Y., Gangaraju, V.K., Qi, H.Y., Liu, N., and Lin, H.F. (2016). Tudor-SN Interacts with Piwi Antagonistically in Regulating Spermatogenesis but Synergistically in Silencing Transposons in Drosophila. Plos Genetics 12, e1005813-e1005813.

Kurscheid, S., Lew-Tabor, A.E., Valle, M.R., Bruyeres, A.G., Doogan, V.J., Munderloh, U.G., Guerrero, F.D., Barrero, R.A., and Bellgard, M.I. (2009). Evidence of a tick RNAi pathway by comparative genomics and reverse genetics screen of targets with known loss-of-function phenotypes in Drosophila. BMC Molecular Biology 10, 26-26.

Kuzuoglu-Ozturk, D., Bhandari, D., Huntzinger, E., Fauser, M., Helms, S., and Izaurralde, E. (2016). miRISC and the CCR4-NOT complex silence mRNA targets independently of 43S ribosomal scanning. EMBO J.

Labreuche, Y., Veloso, A., de la Vega, E., Gross, P.S., Chapman, R.W., Browdy, C.L., and Warr, G.W. (2010). Non-specific activation of antiviral immunity and induction of RNA interference may engage the same pathway in the Pacific white leg shrimp Litopenaeus vannamei. Developmental and Comparative Immunology 34, 1209-1218.

Landthaler, M., Yalcin, A., and Tuschl, T. (2004). The human DiGeorge syndrome critical region gene 8 and its D-melanogaster homolog are required for miRNA biogenesis. Current Biology 14, 2162-2167.

Lau, P.W., Guiley, K.Z., De, N., Potter, C.S., Carragher, B., and MacRae, I.J. (2012). The molecular architecture of human Dicer. Nature Structural \& Molecular Biology 19, 436-440.

Lee, M., Choi, Y., Kim, K., Jin, H., Lim, J., Nguyen, T.A., Yang, J., Jeong, M., Giraldez, A.J., Yang, H., et al. (2014). Adenylation of maternally inherited microRNAs by Wispy. Molecular Cell 56, 696-707.

Lee, Y.S., Nakahara, K., Pham, J.W., Kim, K., He, Z.Y., Sontheimer, E.J., and Carthew, R.W. (2004). Distinct roles for Drosophila Dicer-1 and Dicer-2 in the siRNA/miRNA silencing pathways. Cell 117, 69-81.

Leebonoi, W., Sukthaworn, S., Panyim, S., and Udomkit, A. (2015). A novel gonad-specific Argonaute 4 serves as a defense against transposons in the black tiger shrimp Penaeus monodon. Fish \& Shellfish Immunology 42, 280-288. 
Leger, P., Lara, E., Jagla, B., Sismeiro, O., Mansuroglu, Z., Coppee, J.Y., Bonnefoy, E., and Bouloy, M. (2013). Dicer-2-and Piwi-Mediated RNA Interference in Rift Valley Fever Virus-Infected Mosquito Cells. Journal of Virology 87, 1631-1648.

Lewis, S.H., Salmela, H., and Obbard, D.J. (2016). Duplication and Diversification of Dipteran Argonaute Genes, and the Evolutionary Divergence of Piwi and Aubergine. Genome biology and evolution 8, 507-518.

Li, H., Li, W.X., and Ding, S.W. (2002). Induction and suppression of RNA silencing by an animal virus. Science 296, 1319-1321.

Li, W.H., Prazak, L., Chatterjee, N., Gruninger, S., Krug, L., Theodorou, D., and Dubnau, J. (2013). Activation of transposable elements during aging and neuronal decline in Drosophila. Nature Neuroscience 16, 529-+.

Lim, S.J., Scott, A., Xiong, X.P., Vahidpour, S., Karijolich, J., Guo, D.D., Pei, S.S., Yu, Y.T., Zhou, R., and Li, W.X. (2014). Requirement for CRIF1 in RNA interference and Dicer-2 stability. RNA Biology 11, 1171-1179.

Lipardi, C., and Paterson, B.M. (2009). Identification of an RNA-dependent RNA polymerase in Drosophila involved in RNAi and transposon suppression (Retracted article. See vol. 108, pg. 15010, 2011). Proceedings of the National Academy of Sciences of the United States of America $106,15645-15650$.

Lipardi, C., and Paterson, B.M. (2011). Retraction for Lipardi and Paterson, "Identification of an RNA-dependent RNA polymerase in Drosophila involved in RNAi and transposon suppression". Proceedings of the National Academy of Sciences of the United States of America 108, 15010.

Lipardi, C., Wei, Q., and Paterson, B.M. (2001). RNAi as random degradative PCR: siRNA primers convert mRNA into dsRNAs that are degraded to generate new siRNAs. Cell 107, 297-307.

Liu, N., Abe, M., Sabin, L.R., Hendriks, G.J., Naqvi, A.S., Yu, Z.M., Cherry, S., and Bonini, N.M. (2011). The Exoribonuclease Nibbler Controls 3 ' End Processing of MicroRNAs in Drosophila. Current Biology 21, 1888-1893.

Liu, Q.H., Rand, T.A., Kalidas, S., Du, F.H., Kim, H.E., Smith, D.P., and Wang, X.D. (2003). R2D2, a bridge between the initiation and effector steps of the Drosophila RNAi pathway. Science 301, 1921-1925.

Liu, W., Liu, J.B., Lu, Y.H., Gong, Y.C., Zhu, M., Chen, F., Liang, Z., Zhu, L.Y., Kuang, S.L., Hu, X.L., et al. (2015). Immune signaling pathways activated in response to different pathogenic micro-organisms in Bombyx mori. Molecular Immunology 65, 391-397.

Liu, Y., Ye, X.C., Jiang, F., Liang, C.Y., Chen, D.M., Peng, J.M., Kinch, L.N., Grishin, N.V., and Liu, Q.H. (2009). C3PO, an Endoribonuclease That Promotes RNAi by Facilitating RISC Activation. Science $325,750-753$.

Lozano, J., Gomez-Orte, E., Lee, H.J., and Belles, X. (2012). Super-induction of Dicer-2 expression by alien double-stranded RNAs: an evolutionary ancient response to viral infection? Development Genes and Evolution 222, 229-235.

Lucchetta, E.M., Carthew, R.W., and Ismagilov, R.F. (2009). The Endo-siRNA Pathway Is Essential for Robust Development of the Drosophila Embryo. Plos One 4, e7576-e7576.

Luhur, A., Chawla, G., Wu, Y.C., Li, J., and Sokol, N.S. (2014). Drosha-independent DGCR8/Pasha pathway regulates neuronal morphogenesis. Proceedings of the National Academy of Sciences of the United States of America 111, 1421-1426. 
Luo, Y., Wang, X.H., Yu, D., and Kang, L. (2012). The SID-1 double-stranded RNA transporter is not required for systemic RNAi in the migratory locust. RNA Biology 9, 663-671.

MacRae, I.J., Zhou, K., and Doudna, J.A. (2007). Structural determinants of RNA recognition and cleavage by Dicer. Nature Structural and Molecular Biology 14, 934-940.

MacRae, I.J., Zhou, K., Li, F., Repic, A., Brooks, A.N., Cande, W.Z., Adams, P.D., and Doudna, J.A. (2006). Structural basis for double-stranded RNA processing by Dicer. Science 311, 195-198.

Maralit, B.A., Komatsu, M., Hipolito, S.G., Hirono, I., and Kondo, H. (2015). Microarray Analysis of Immunity Against WSSV in Response to Injection of Non-specific Long dsRNA in Kuruma Shrimp, Marsupenaeus japonicus. Marine Biotechnology 17, 493-501.

Margulis, L., and Schwartz, K.V. (1998). Five kingdoms : an illustrated guide to the phyla of life on earth, 3rd edn (New York: W.H. Freeman).

Marques, J.T., Kim, K., Wu, P.H., Alleyne, T.M., Jafari, N., and Carthew, R.W. (2010). Loqs and R2D2 act sequentially in the siRNA pathway in Drosophila. Nature Structural \& Molecular Biology 17, 24-U37.

Martin, R., Smibert, P., Yalcin, A., Tyler, D.M., Schafer, U., Tuschl, T., and Lai, E.C. (2009). A Drosophila pasha Mutant Distinguishes the Canonical MicroRNA and Mirtron Pathways. Molecular and Cellular Biology 29, 861-870.

Matranga, C., Tomari, Y., Shin, C., Bartel, D.P., and Zamore, P.D. (2005). Passenger-strand cleavage facilitates assembly of siRNA into Ago2-containing RNAi enzyme complexes. Cell 123, 607-620.

Miyoshi, K., Miyoshi, T., Hartig, J.V., Siomi, H., and Siomi, M.C. (2010a). Molecular mechanisms that funnel RNA precursors into endogenous small-interfering RNA and microRNA biogenesis pathways in Drosophila. RNA 16, 506-515.

Miyoshi, K., Okada, T.N., Siomi, H., and Siomi, M.C. (2009). Characterization of the miRNA-RISC loading complex and miRNA-RISC formed in the Drosophila miRNA pathway. RNA 15, 1282-1291.

Miyoshi, K., Tsukumo, H., Nagami, T., Siomi, H., and Siomi, M.C. (2005). Slicer function of Drosophila Argonautes and its involvement in RISC formation. Genes \& Development 19, 2837-2848.

Miyoshi, T., Takeuchi, A., Siomi, H., and Siomi, M.C. (2010b). A direct role for Hsp90 in pre-RISC formation in Drosophila. Nature Structural \& Molecular Biology 17, 1024-1026.

Mon, H., Li, Z., Kobayashi, I., Tomita, S., Lee, J., Sezutsu, H., Tamura, T., and Kusakabe, T. (2013). Soaking RNAi in Bombyx mori BmN4-SID1 cells arrests cell cycle progression. Journal of Insect Science 13, 155-155.

Morazzani, E.M., Wiley, M.R., Murreddu, M.G., Adelman, Z.N., and Myles, K.M. (2012). Production of Virus-Derived Ping-Pong-Dependent piRNA-like Small RNAs in the Mosquito Soma. Plos Pathogens 8, e1002470-e1002470.

Moretti, F., Kaiser, C., Zdanowicz-Specht, A., and Hentze, M.W. (2012). PABP and the poly(A) tail augment microRNA repression by facilitated miRISC binding. Nature Structural \& Molecular Biology 19, 603-+.

Moshkovich, N., Nisha, P., Boyle, P.J., Thompson, B.A., Dale, R.K., and Lei, E.P. (2011). RNAi-independent role for Argonaute2 in CTCF/CP190 chromatin insulator function. Genes \& Development $25,1686-1701$.

Mugat, B., Akkouche, A., Serrano, V., Armenise, C., Li, B., Brun, C., Fulga, T.A., Van Vactor, D., Pelisson, A., and Chambeyron, S. (2015). MicroRNA-Dependent Transcriptional Silencing of Transposable Elements in Drosophila Follicle Cells. Plos Genetics 11, e1005194-e1005194. 
Murota, Y., Ishizu, H., Nakagawa, S., Iwasaki, Y.W., Shibata, S., Kamatani, M.K., Saito, K., Okano, H., Siomi, H., and Siomi, M.C. (2014). Yb Integrates piRNA Intermediates and Processing Factors into Perinuclear Bodies to Enhance piRISC Assembly. Cell Reports 8, 103-113.

Murphy, D., Dancis, B., and Brown, J.R. (2008). The evolution of core proteins involved in microRNA biogenesis. BMC Evolutionary Biology 8, 92-92.

Nagao, A., Mituyama, T., Huang, H.D., Chen, D.H., Siomi, M.C., and Siomi, H. (2010). Biogenesis pathways of piRNAs loaded onto AGO3 in the Drosophila testis. RNA 16, 2503-2515.

Nayak, A., Berry, B., Tassetto, M., Kunitomi, M., Acevedo, A., Deng, C.H., Krutchinsky, A., Gross, J., Antoniewski, C., and Andino, R. (2010). Cricket paralysis virus antagonizes Argonaute 2 to modulate antiviral defense in Drosophila. Nature Structural \& Molecular Biology 17, 547-U541.

Nishida, K.M., Miyoshi, K., Ogino, A., Miyoshi, T., Siomi, H., and Siomi, M.C. (2013). Roles of R2D2, a Cytoplasmic D2 Body Component, in the Endogenous siRNA Pathway in Drosophila. Molecular Cell 49, 680-691.

Niu, J.Z., Smagghe, G., De Coninck, D.I.M., Van Nieuwerburgh, F., Deforce, D., and Meeus, I. (2016). In vivo study of Dicer-2-mediated immune response of the small interfering RNA pathway upon systemic infections of virulent and avirulent viruses in Bombus terrestris. Insect Biochemistry and Molecular Biology 70, 127-137.

Nykanen, A., Haley, B., and Zamore, P.D. (2001). ATP requirements and small interfering RNA structure in the RNA interference pathway. Cell 107, 309-321.

Okamura, K., Balla, S., Martin, R., Liu, N., and Lai, E.C. (2008a). Two distinct mechanisms generate endogenous siRNAs from bidirectional transcription in Drosophila melanogaster. Nature Structural \& Molecular Biology 15, 581-590.

Okamura, K., Chung, W.J., and Lai, E.C. (2008b). The long and short of inverted repeat genes in animals - microRNAs, mirtrons and hairpin RNAs. Cell Cycle 7, 2840-2845.

Okamura, K., Chung, W.J., Ruby, J.G., Guo, H.L., Bartel, D.P., and Lai, E.C. (2008c). The Drosophila hairpin RNA pathway generates endogenous short interfering RNAs. Nature 453, 803-U808.

Okamura, K., Hagen, J.W., Duan, H., Tyler, D.M., and Lai, E.C. (2007). The mirtron pathway generates microRNA-class regulatory RNAs in Drosophila. Cell 130, 89-100.

Okamura, K., Ladewig, E., Zhou, L., and Lai, E.C. (2013). Functional small RNAs are generated from select miRNA hairpin loops in flies and mammals. Genes \& Development 27, 778-792.

Okamura, K., Liu, N., and Lai, E.C. (2009). Distinct Mechanisms for MicroRNA Strand Selection by Drosophila Argonautes. Molecular Cell 36, 431-444.

Okamura, K., Robine, N., Liu, Y., Liu, Q.H., and Lai, E.C. (2011). R2D2 Organizes Small Regulatory RNA Pathways in Drosophila. Molecular and Cellular Biology 31, 884-896.

Ortiz-Rivas, B., Jaubert-Possamai, S., Tanguy, S., Gauthier, J.P., Tagu, D., and Claude, R. (2012). Evolutionary study of duplications of the miRNA machinery in aphids associated with striking rate acceleration and changes in expression profiles. BMC Evolutionary Biology 12, 216-216.

Palladino, M.J., Keegan, L.P., O’Connell, M.A., and Reenan, R.A. (2000). dADAR, a Drosophila double-stranded RNA-specific adenosine deaminase is highly developmentally regulated and is itself a target for RNA editing. RNA 6, 1004-1018.

Palmer, W.J., and Jiggins, F.M. (2015). Comparative Genomics Reveals the Origins and Diversity of Arthropod Immune Systems. Molecular Biology and Evolution 32, 2111-2129.

Paradkar, P.N., Trinidad, L., Voysey, R., Duchemin, J.B., and Walker, P.J. (2012). Secreted Vago restricts West Nile virus infection in Culex mosquito cells by activating the Jak-STAT 
pathway. Proceedings of the National Academy of Sciences of the United States of America 109, 18915-18920.

Paro, S., Li, X.H., O’Connell, M.A., and Keegan, L.P. (2012). Regulation and Functions of ADAR in Drosophila. In Adenosine Deaminases Acting on Rna, pp. 221-236.

Pasquinelli, A.E., Reinhart, B.J., Slack, F., Martindale, M.Q., Kuroda, M.I., Maller, B., Hayward, D.C., Ball, E.E., Degnan, B., Muller, P., et al. (2000). Conservation of the sequence and temporal expression of let-7 heterochronic regulatory RNA. Nature 408, 86-89.

Peters, L., and Meister, G. (2007). Argonaute proteins: mediators of RNA silencing. Molecular Cell 26, 611-623.

Peters, N.T., Rohrbach, J.A., Zalewski, B.A., Byrkett, C.M., and Vaughn, J.C. (2003). RNA editing and regulation of Drosophila $4 \mathrm{f}-\mathrm{rnp}$ expression by sas-10 antisense readthrough mRNA transcripts. RNA 9, 698-710.

Pham, J.W., Pellino, J.L., Lee, Y.S., Carthew, R.W., and Sontheimer, E.J. (2004). A Dicer-2-dependent 80S complex cleaves targeted mRNAs during RNAi in Drosophila. Cell 117, 83-94.

Phetrungnapha, A., Ho, T., Udomkit, A., Panyim, S., and Ongvarrasopone, C. (2013). Molecular cloning and functional characterization of Argonaute-3 gene from Penaeus monodon. Fish \& Shellfish Immunology 35, 874-882.

Pinder, B.D., and Smibert, C.A. (2013). microRNA-independent recruitment of Argonaute 1 to nanos mRNA through the Smaug RNA-binding protein. EMBO Rep 14, 80-86.

Pressman, S., Reinke, C.A., Wang, X.H., and Carthew, R.W. (2012). A Systematic Genetic Screen to Dissect the MicroRNA Pathway in Drosophila. G3-Genes Genomes Genetics 2, 437-448.

Provost, P., Dishart, D., Doucet, J., Frendewey, D., Samuelsson, B., and Radmark, O. (2002). Ribonuclease activity and RNA binding of recombinant human Dicer. EMBO J 21, 5864-5874.

Pushpavalli, S., Bag, I., Pal-Bhadra, M., and Bhadra, U. (2012). Drosophila Argonaute-1 is critical for transcriptional cosuppression and heterochromatin formation. Chromosome Research 20, 333-351.

Qi, H., Watanabe, T., Ku, H.-Y., Liu, N., Zhong, M., and Lin, H. (2011). The Yb Body, a Major Site for Piwi-associated RNA Biogenesis and a Gateway for Piwi Expression and Transport to the Nucleus in Somatic Cells. Journal of Biological Chemistry 286, 3789-3797.

Regier, J.C., Shultz, J.W., Zwick, A., Hussey, A., Ball, B., Wetzer, R., Martin, J.W., and Cunningham, C.W. (2010). Arthropod relationships revealed by phylogenomic analysis of nuclear protein-coding sequences. Nature 463, 1079-1083.

Rehwinkel, J., Behm-Ansmant, I., Gatfield, D., and Izaurralde, E. (2005). A crucial role for GW182 and the DCP1 : DCP2 decapping complex in miRNA-mediated gene silencing. RNA 11, 1640-1647.

Reimao-Pinto, M.M., Ignatova, V., Burkard, T.R., Hung, J.H., Manzenreither, R.A., Sowemimo, I., Herzog, V.A., Reichholf, B., Farina-Lopez, S., and Ameres, S.L. (2015). Uridylation of RNA Hairpins by Tailor Confines the Emergence of MicroRNAs in Drosophila. Molecular Cell 59, 203-216.

Roignant, J.Y., Carre, C., Mugat, B., Szymczak, D., Lepesant, J.A., and Antoniewski, C. (2003). Absence of transitive and systemic pathways allows cell-specific and isoform-specific RNAi in Drosophila. RNA 9, 299-308.

Ruby, J.G., Jan, C.H., and Bartel, D.P. (2007). Intronic microRNA precursors that bypass Drosha processing. Nature $448,83-86$. 
Sabin, L.R., and Cherry, S. (2013). Small creatures use small RNAs to direct antiviral defenses. European Journal of Immunology 43, 27-33.

Saito, K., Ishizu, H., Komai, M., Kotani, H., Kawamura, Y., Nishida, K.M., Siomi, H., and Siomi, M.C. (2010). Roles for the $\mathrm{Yb}$ body components Armitage and $\mathrm{Yb}$ in primary piRNA biogenesis in Drosophila. Genes \& Development 24, 2493-2498.

Saito, K., Ishizuka, A., Siomi, H., and Siomi, M.C. (2005). Processing of pre-microRNAs by the Dicer-1-Loquacious complex in Drosophila cells. Plos Biology 3, 1202-1212.

Saito, K., Sakaguchi, Y., Suzuki, T., Suzuki, T., Siomi, H., and Siomi, M.C. (2007). Pimet, the Drosophila homolog of HEN1, mediates 2 '-O-methylation of PIWI-interacting RNAs at their 3 ' ends. Genes \& Development 21, 1603-1608.

Saleh, M.C., Tassetto, M., van Rij, R.P., Goic, B., Gausson, V., Berry, B., Jacquier, C., Antoniewski, C., and Andino, R. (2009). Antiviral immunity in Drosophila requires systemic RNA interference spread. Nature 458, 346-350.

Sanchez-Vargas, I., Scott, J.C., Poole-Smith, B.K., Franz, A.W.E., Barbosa-Solomieu, V., Wilusz, J., Olson, K.E., and Blair, C.D. (2009). Dengue Virus Type 2 Infections of Aedes aegypti Are Modulated by the Mosquito's RNA Interference Pathway. Plos Pathogens 5, e1000299-e1000299.

Sato, K., and Siomi, M.C. (2013). Piwi-interacting RNAs: biological functions and biogenesis. Essays in biochemistry $54,39-52$.

Schnettler, E., Donald, C.L., Human, S., Watson, M., Siu, R.W.C., McFarlane, M., Fazakerley, J.K., Kohl, A., and Fragkoudis, R. (2013a). Knockdown of piRNA pathway proteins results in enhanced Semliki Forest virus production in mosquito cells. Journal of General Virology 94, 1680-1689.

Schnettler, E., Ratinier, M., Watson, M., Shaw, A.E., McFarlane, M., Varela, M., Elliott, R.M., Palmarini, M., and Kohl, A. (2013b). RNA Interference Targets Arbovirus Replication in Culicoides Cells. Journal of Virology 87, 2441-2454.

Schnettler, E., Tykalova, H., Watson, M., Sharma, M., Sterken, M.G., Obbard, D.J., Lewis, S.H., McFarlane, M., Bell-Sakyi, L., Barry, G., et al. (2014). Induction and suppression of tick cell antiviral RNAi responses by tick-borne flaviviruses. Nucleic Acids Research 42, 9436-9446.

Schuster, S., Zirkel, F., Kurth, A., van Cleef, K.W.R., Drosten, C., van Rij, R.P., and Junglen, S. (2014). A Unique Nodavirus with Novel Features: Mosinovirus Expresses Two Subgenomic RNAs, a Capsid Gene of Unknown Origin, and a Suppressor of the Antiviral RNA Interference Pathway. Journal of Virology 88, 13447-13459.

Schwarz, D.S., Hutvagner, G., Haley, B., and Zamore, P.D. (2002). Evidence that siRNAs function as guides, not primers, in the Drosophila and human RNAi pathways. Molecular Cell 10, 537-548.

Schwarz, D.S., Tomari, Y., and Zamore, P.D. (2004). The RNA-induced silencing complex is a Mg2+-dependent endonuclease. Current Biology 14, 787-791.

Shih, J.D., and Hunter, C.P. (2011). SID-1 is a dsRNA-selective dsRNA-gated channel. RNA 17, 1057-1065.

Shreve, J.T., Shukle, R.H., Subramanyam, S., Johnson, A.J., Schemerhorn, B.J., Williams, C.E., and Stuart, J.J. (2013). A genome-wide survey of small interfering RNA and microRNA pathway genes in a galling insect. Journal of Insect Physiology 59, 367-376.

Sinha, N.K., Trettin, K.D., Aruscavage, P.J., and Bass, B.L. (2015). Drosophila Dicer-2 Cleavage Is Mediated by Helicase- and dsRNA Termini-Dependent States that Are Modulated by Loquacious-PD. Molecular Cell 58, 406-417. 
Smibert, P., Bejarano, F., Wang, D., Garaulet, D.L., Yang, J.S., Martin, R., Bortolamiol-Becet, D., Robine, N., Hiesinger, P.R., and Lai, E.C. (2011). A Drosophila genetic screen yields allelic series of core microRNA biogenesis factors and reveals post-developmental roles for microRNAs. RNA 17, 1997-2010.

Song, J.S., Guo, W., Jiang, F., Kang, L., and Zhou, S.T. (2013). Argonaute 1 is indispensable for juvenile hormone mediated oogenesis in the migratory locust, Locusta migratoria. Insect Biochemistry and Molecular Biology 43, 879-887.

Su, J.S., Oanh, D.T.H., Lyons, R.E., Leeton, L., van Hulten, M.C.W., Tan, S.H., Song, L., Rajendran, K.V., and Walker, P.J. (2008). A key gene of the RNA interference pathway in the black tiger shrimp, Penaeus monodon: Identification and functional characterisation of Dicer-1. Fish \& Shellfish Immunology 24, 223-233.

Svoboda, P. (2019). Introduction to RNAi and miRNA pathways.

Taliaferro, J.M., Aspden, J.L., Bradley, T., Marwha, D., Blanchette, M., and Rio, D.C. (2013). Two new and distinct roles for Drosophila Argonaute-2 in the nucleus: alternative pre-mRNA splicing and transcriptional repression. Genes \& Development 27, 378-389.

Tomari, Y., Du, T., and Zamore, P.D. (2007). Sorting of Drosophila small silencing RNAs. Cell 130, 299-308.

Tomari, Y., Du, T.T., Haley, B., Schwarz, D.S., Bennett, R., Cook, H.A., Koppetsch, B.S., Theurkauf, W.E., and Zamore, P.D. (2004a). RISC assembly defects in the Drosophila RNAi mutant armitage. Cell 116, 831-841.

Tomari, Y., Matranga, C., Haley, B., Martinez, N., and Zamore, P.D. (2004b). A protein sensor for siRNA asymmetry. Science 306, 1377-1380.

Tomari, Y., and Zamore, P.D. (2005). Perspective: machines for RNAi. Genes Dev 19, 517-529.

Tomoyasu, Y., Miller, S.C., Tomita, S., Schoppmeier, M., Grossmann, D., and Bucher, G. (2008). Exploring systemic RNA interference in insects: a genome-wide survey for RNAi genes in Tribolium. Genome Biology 9, R10-R10.

Tsutsumi, A., Kawamata, T., Izumi, N., Seitz, H., and Tomari, Y. (2011). Recognition of the pre-miRNA structure by Drosophila Dicer-1. Nature Structural \& Molecular Biology 18, 1153-U1189. van Cleef, K.W.R., van Mierlo, J.T., Miesen, P., Overheul, G.J., Fros, J.J., Schuster, S., Marklewitz, M., Pijlman, G.P., Junglen, S., and van Rij, R.P. (2014). Mosquito and Drosophila entomobirnaviruses suppress dsRNA- and siRNA-induced RNAi. Nucleic Acids Research 42, 8732-8744.

van Rij, R.P., Saleh, M.C., Berry, B., Foo, C., Houk, A., Antoniewski, C., and Andino, R. (2006). The RNA silencing endonuclease Argonaute 2 mediates specific antiviral immunity in Drosophila melanogaster. Genes \& Development 20, 2985-2995.

Vodovar, N., Bronkhorst, A.W., van Cleef, K.W.R., Miesen, P., Blanc, H., van Rij, R.P., and Saleh, M.C. (2012). Arbovirus-Derived piRNAs Exhibit a Ping-Pong Signature in Mosquito Cells. Plos One 7, e30861-e30861.

Wang, H., Ma, Z.J., Niu, K.Y., Xiao, Y., Wu, X.F., Pan, C.Y., Zhao, Y., Wang, K., Zhang, Y.Y., and Liu, N. (2016). Antagonistic roles of Nibbler and Hen1 in modulating piRNA 3 ' ends in Drosophila. Development 143, 530-539.

Wang, H.D., Gong, L., Qi, J.W., Hu, M.Y., Zhong, G.H., and Gong, L. (2014). Molecular cloning and characterization of a SID-1-like gene in Plutella xylostella. Archives of Insect Biochemistry and Physiology 87, 164-176. 
Wang, P.H., Weng, S.P., and He, J.G. (2015a). Nucleic acid-induced antiviral immunity in invertebrates: An evolutionary perspective. Developmental and Comparative Immunology 48, 291-296.

Wang, P.H., Yang, L.S., Gu, Z.H., Weng, S.P., Yu, X.Q., and He, J.G. (2013). Nucleic acid-induced antiviral immunity in shrimp. Antiviral Research 99, 270-280.

Wang, X.H., Aliyari, R., Li, W.X., Li, H.W., Kim, K., Carthew, R., Atkinson, P., and Ding, S.W. (2006). RNA interference directs innate immunity against viruses in adult Drosophila. Science $312,452-454$.

Wang, Z., Wu, D., Liu, Y., Xia, X., Gong, W., Qiu, Y., Yang, J., Zheng, Y., Li, J., Wang, Y.F., et al. (2015b). Drosophila Dicer-2 has an RNA interference-independent function that modulates Toll immune signaling. Science advances 1, e1500228-e1500228.

Welker, N.C., Maity, T.S., Ye, X.C., Aruscavage, P.J., Krauchuk, A.A., Liu, Q.H., and Bass, B.L. (2011). Dicer's Helicase Domain Discriminates dsRNA Termini to Promote an Altered Reaction Mode. Molecular Cell 41, 589-599.

Wen, J.Y., Duan, H., Bejarano, F., Okamura, K., Fabian, L., Brill, J.A., Bortolamiol-Becet, D., Martin, R., Ruby, J.G., and Lai, E.C. (2015). Adaptive Regulation of Testis Gene Expression and Control of Male Fertility by the Drosophila Harpin RNA Pathway. Molecular Cell 57, 165-178.

Westholm, J.O., Ladewig, E., Okamura, K., Robine, N., and Lai, E.C. (2012). Common and distinct patterns of terminal modifications to mirtrons and canonical microRNAs. RNA 18, 177-192.

Winter, F., Edaye, S., Huttenhofer, A., and Brunel, C. (2007). Anopheles gambiae miRNAs as actors of defence reaction against Plasmodium invasion. Nucleic Acids Research 35, 6953-6962.

Wynant, N., Santos, D., Subramanyam, S.H., Verlinden, H., and Broeck, J.V. (2015). Drosha, Dicer-1 and Argonaute-1 in the desert locust: Phylogenetic analyses, transcript profiling and regulation during phase transition and feeding. Journal of Insect Physiology 75, 20-29.

Xiong, X.P., Vogler, G., Kurthkoti, K., Samsonova, A., and Zhou, R. (2015). SmD1 Modulates the miRNA Pathway Independently of Its Pre-mRNA Splicing Function. Plos Genetics 11, e1005475-e1005475.

Xu, H.J., Chen, T., Ma, X.F., Xue, J., Pan, P.L., Zhang, X.C., Cheng, J.A., and Zhang, C.X. (2013). Genome-wide screening for components of small interfering RNA (siRNA) and micro-RNA (miRNA) pathways in the brown planthopper, Nilaparvata lugens (Hemiptera: Delphacidae). Insect Molecular Biology 22, 635-647.

Xu, K.Y., Bogert, B.A., Li, W.J., Su, K., Lee, A., and Gao, F.B. (2004). The fragile X-related gene affects the crawling behavior of Drosophila larvae by regulating the mRNA level of the DEG/ ENaC protein pickpocket1. Current Biology 14, 1025-1034.

$\mathrm{Xu}, \mathrm{W}$., and Han, Z. (2008). Cloning and phylogenetic analysis of sid-1-like genes from aphids. Journal of insect science (Online) 8, 1-6.

Yang, J.S., Smibert, P., Westholm, J.O., Jee, D., Maurin, T., and Lai, E.C. (2014a). Intertwined pathways for Argonaute-mediated microRNA biogenesis in Drosophila. Nucleic Acids Research 42, 1987-2002.

Yang, L.L., Chen, D.S., Duan, R.H., Xia, L.X., Wang, J., Qurashi, A., Jin, P., and Chen, D.H. (2007). Argonaute 1 regulates the fate of germline stem cells in Drosophila. Development 134, 4265-4272.

Yang, L.S., Li, X.L., Jiang, S., Qiu, L.H., Zhou, F.L., Liu, W.J., and Jiang, S.G. (2014b). Characterization of Argonaute2 gene from black tiger shrimp (Penaeus monodon) and its responses to immune challenges. Fish \& Shellfish Immunology 36, 261-269. 
Ye, X.C., Paroo, Z., and Liu, Q.H. (2007). Functional anatomy of the Drosophila MicroRNA- generating enzyme. Journal of Biological Chemistry 282, 28373-28378.

Yoda, M., Kawamata, T., Paroo, Z., Ye, X.C., Iwasaki, S., Liu, Q.H., and Tomari, Y. (2010). ATP-dependent human RISC assembly pathways. Nature Structural \& Molecular Biology 17, 17-U29.

Zambon, R.A., Vakharia, V.N., and Wu, L.P. (2006). RNAi is an antiviral immune response against a dsRNA virus in Drosophila melanogaster. Cellular Microbiology 8, 880-889.

Zhang, H., Kolb, F.A., Brondani, V., Billy, E., and Filipowicz, W. (2002). Human Dicer preferentially cleaves dsRNAs at their termini without a requirement for ATP. EMBO J 21, 5875-5885.

Zhang, X.Y., Lu, K., Zhou, J.L., and Zhou, Q. (2013). Molecular characterization and gene functional analysis of Dicer-2 gene from Nilaparvata lugens (Hemiptera: Geometroidea). Insect Science 20, $61-68$.

Zhao, C.Y., Gonzales, M.A.A., Poland, T.M., and Mittapalli, O. (2015). Core RNAi machinery and gene knockdown in the emerald ash borer (Agrilus planipennis). Journal of Insect Physiology 72, 70-78.

Zhou, R., Czech, B., Brennecke, J., Sachidanandam, R., Wohlschlegel, J.A., Perrimon, N., and Hannon, G.J. (2009). Processing of Drosophila endo-siRNAs depends on a specific Loquacious isoform. RNA 15, 1886-1895.

Zhu, L., Tatsuke, T., Li, Z.Q., Mon, H., Xu, J., Lee, J.M., and Kusakabe, T. (2012). Molecular cloning of BmTUDOR-SN and analysis of its role in the RNAi pathway in the silkworm, Bombyx mori (Lepidoptera: Bombycidae). Applied Entomology and Zoology 47, 207-215.

Zografidis, A., Van Nieuwerburgh, F., Kolliopoulou, A., Apostolou-Karampelis, K., Head, S.R., Deforce, D., Smagghe, G., and Swevers, L. (2015). Viral Small-RNA Analysis of Bombyx mori Larval Midgut during Persistent and Pathogenic Cytoplasmic Polyhedrosis Virus Infection. Journal of Virology 89, 11473-11486. 